\title{
Negative Reactant Ion Formation in High Kinetic Energy lon Mobility Spectrometry (HiKE-IMS)
}

\author{
Maria Allers*1, Ansgar T. Kirk ${ }^{1}$, Bennet Timke ${ }^{1}$, Duygu Erdogdu², Walter Wissdorf ${ }^{2}$, Thorsten Benter ${ }^{2}$, Stefan \\ Zimmermann ${ }^{1}$ \\ ${ }^{1}$ Leibniz University Hannover, Institute of Electrical Engineering and Measurement Technology, Appelstraße 9a, \\ 30167 Hannover, Germany \\ ${ }^{2}$ Department of Physical and Theoretical Chemistry, University of Wuppertal, Gauss Str. 20, 42119 Wuppertal, \\ Germany
}

*Corresponding author: allers@geml.uni-hannover.de

Keywords: Negative reactant ion formation, corona discharge ionization, ion mobility spectrometry, high kinetic energy ion mobility spectrometry, HiKE-IMS, IMS

\begin{abstract}
Due to the operation at background pressures between 10-40 mbar and high reduced electric field strengths of up to $120 \mathrm{Td}$, the ion-molecule reactions in High Kinetic Energy lon Mobility Spectrometers (HiKE-IMS) differ from those in classical ambient pressure IMS. In the positive ion polarity mode, the reactant ions $\mathrm{H}^{+}\left(\mathrm{H}_{2} \mathrm{O}\right)_{n}, \mathrm{O}_{2}^{+}\left(\mathrm{H}_{2} \mathrm{O}\right)_{n}$ and $\mathrm{NO}^{+}\left(\mathrm{H}_{2} \mathrm{O}\right)_{n}$ are observed in the HiKE-IMS. The relative abundances of these reactant ion species significantly depend on the reduced electric field strength in the reaction region, the operating pressure, and water concentration in the reaction region. In this work, the formation of negative reactant ions in HiKE-IMS is investigated in detail. Based on kinetic and thermodynamic data from literature, the processes resulting in the formation of negative reactant ions are kinetically modeled. To verify the model, we present measurements of the negative reactant ion population in the HiKE-IMS and its dependence on the reduced electric field strength as well as the water and carbon dioxide concentration in the reaction region. The ion species underlying individual peaks in the ion mobility spectrum are identified by coupling the HiKE-IMS to a time-of-flight mass spectrometer (TOF-MS) using a simple gated interface that enables the transfer of selected peaks of the ion mobility spectrum into the TOF-MS. Both, the theoretical model as well as the experimental data suggest the predominant generation of the oxygen based ions $\mathrm{O}^{-}, \mathrm{OH}^{-}, \mathrm{O}_{2}{ }^{-}$, and $\mathrm{O}_{3}{ }^{-}$in purified air containing $70 \mathrm{ppm}_{\mathrm{v}}$ of water and $30 \mathrm{ppm}_{\mathrm{v}}$ of carbon dioxide. Additionally, small amounts of $\mathrm{NO}_{2}{ }^{-}$and $\mathrm{CO}_{3}{ }^{-}$are observed. Their relative abundances highly depend on the reduced electric field strength as well as the water and carbon dioxide concentration. An increase of the water concentration in the reaction region results in the generation of $\mathrm{OH}^{-}$ions, whereas increasing the carbon dioxide concentration favors the generation of $\mathrm{CO}_{3}{ }^{-}$ions, as expected.
\end{abstract}

\section{Introduction}

Ion mobility spectrometers (IMS) characterize and separate ions by their motion through a neutral gas under the influence of an electric field. Similar to classical drift tube IMS operating at ambient pressure, ions are generated in a reaction region by corona discharge ionization in High Kinetic Energy IMS (HiKEIMS) before being separated in a drift region. However, in contrast to classical ambient pressure IMS, the HiKE-IMS is operated at background pressures between 10 and 40 mbar and reaches high reduced electric field strengths of up to $120 \mathrm{Td}$ in both, the reaction region and the drift region ${ }^{1-3}$. The reduced electric field strength $E / N$ is the ratio of the electric field strength $E$ to the neutral molecule density $N$, usually given in units of Townsend (Td). As known from Proton Transfer Reaction Mass Spectrometry (PTR-MS) ${ }^{4}$, the operation at reduced pressure and high reduced electric field strengths might be beneficial for two main reasons: First, the temporally much shorter and better defined residence time 
of ions in the reaction region might lead to an enhancement of the linear range and a decrease in chemical cross sensitivities. Second, at elevated reduced electric field strengths, all charge bound cluster formation equilibria are shifted towards smaller sizes, enabling potentially new ionization pathways to ionize e.g. low proton or electron affine substances not detectable when using ambient pressure chemical ionization ${ }^{2}$. Other major benefits are orthogonal ion separation using the fielddependent ion mobility (alpha-function), known from field asymmetric ion mobility spectrometers (FAIMS) and differential ion mobility spectrometers (DMS) ${ }^{5,6}$, and ion collision induced fragmentation for improved compound identification ${ }^{7,8}$. However, due to the operation at decreased pressures and high reduced electric field strengths, the ion-molecule chemistry in the HiKE-IMS generally differs from that in classical ambient pressure IMS. In order to predict the ionization pathways of specific analyte molecules, a detailed knowledge about the dominant reactant ion species generated in HiKE-IMS in dependence on the operating conditions is essential.

By coupling the HiKE-IMS to a mass spectrometer, the occurring positive reactant ions in HiKE-IMS in purified air with different water concentrations were identified as $\mathrm{H}^{+}\left(\mathrm{H}_{2} \mathrm{O}\right)_{n}, \mathrm{O}_{2}{ }^{+}\left(\mathrm{H}_{2} \mathrm{O}\right)_{n}$, and $\mathrm{NO}^{+}\left(\mathrm{H}_{2} \mathrm{O}\right)_{n}$ ${ }^{9}$. Their relative abundances significantly depend on the reduced electric field strength, the operating pressure and the water concentration in the reaction region, as these parameters affect the conversion processes of $\mathrm{O}_{2}^{+}$and $\mathrm{NO}^{+}$to proton bound water clusters $\mathrm{H}^{+}\left(\mathrm{H}_{2} \mathrm{O}\right)_{n}{ }^{10}$.

Compared to the spectra of positive reactant ions, the HiKE-IMS spectra of negative reactant ions are more complex. Instead of three distinct peaks, at least five peaks are observed in the negative reactant ion spectrum. Until now, only limited knowledge about the ion formation processes in the HiKE-IMS in the negative ion polarity mode is available. However, some compounds, such as halocarbons, organic acids or explosives are mainly detected in the negative ion polarity mode. Thus, a detailed knowledge about the negative reactant ion population dominant in the reaction region is essential to predict the ionization pathways in HiKE-IMS operated in the negative ion polarity mode.

The formation of negative ions in corona discharges ionization sources has been investigated in many studies in the last decades ${ }^{11-18}$. It has been shown that the yield of the individual ion species is strongly affected by trace concentrations of ozone, nitrogen oxides, carbon dioxide, and water. Thus, the negative ion species and their relative abundances observed in these studies differ significantly due to varying experimental conditions. For example, in the pioneering work of Shahin ${ }^{11}, \mathrm{NO}_{2}{ }^{-}$and $\mathrm{NO}_{3}{ }^{-}$ions were found to be predominant in negative corona discharge ionization sources whereas other groups detected various additional ion species such as $\mathrm{O}_{3}{ }^{-}, \mathrm{OH}^{-}, \mathrm{CO}_{3}{ }^{-}$or $\mathrm{HCO}_{3}{ }^{-12,13,15-18}$. Furthermore, Ross and Bell ${ }^{14}$ pointed out the important role of radicals and neutrals in negative ion formation in corona discharge ionization sources. When removing radicals and neutrals from the corona discharge by a reverse gas flow, $\mathrm{O}_{2}^{-}$and $\mathrm{CO}_{4}^{-}$ions occurred.

The aim of this work is to identify the occurring negative reactant ion species in HiKE-IMS and to understand the mechanisms underlying their formation. Therefore, the HiKE-IMS is coupled to a mass spectrometer (MS) as presented in detail in a previous work ${ }^{9}$. Furthermore, based on thermodynamic and kinetic data from literature, a simple kinetic model is developed predicting the ion formation processes. To verify the model, the negative reactant ion population in HiKE-IMS in air is experimentally investigated as a function of the reduced electric field strength in the reaction region as well as the water and carbon dioxide concentration in the reaction region.

\section{Experimental section}

\section{HiKE-IMS}

The HiKE-IMS setup used in this work equals the setup reported previously ${ }^{3}$. A schematic of the setup is shown in Figure 1 and the default operating parameters are given in Table 1. The HiKE-IMS consists 
of a corona discharge ionization source, a reaction region, and a drift region. It is operated at a constant pressure of $14.3 \mathrm{mbar}$. By inverting all applied voltages, it is possible to switch between the positive and negative ion polarity mode. The reduced electric field strength in the reaction and in the drift region can be independently increased up to $120 \mathrm{Td}$ in the positive ion polarity mode. However, in the negative ion polarity mode, electrical breakdowns occur due to the high amount of electrons injected into the HiKE-IMS coming from the corona discharge. Thus, in the negative ion polarity mode, the maximum reduced electric field strength in the reaction and the drift region is limited to $100 \mathrm{Td}$. In this work, the HiKE-IMS is operated at a constant temperature of $45^{\circ} \mathrm{C}$. Drift and sample gas are transferred into the HiKE-IMS via capillaries with $250 \mu \mathrm{m}$ inner diameter and adjusted lengths to provide gas flow rates of $19 \mathrm{ml}_{\mathrm{s}} / \mathrm{min}$ (milliliter standard per minute, mass flow at reference conditions $20^{\circ} \mathrm{C}$ and 1013.25 $\mathrm{hPa}$ ) for both, the drift gas and sample gas. The drift gas flows through the drift tube and mixes within the reaction region with the sample gas. In close vicinity to the corona needle, the HiKE-IMS is evacuated via a membrane pump (Pfeiffer Vacuum, MVP 40). The pressure within the HiKE-IMS is monitored with a capacitive pressure gauge (Pfeiffer Vacuum, CMR 362).

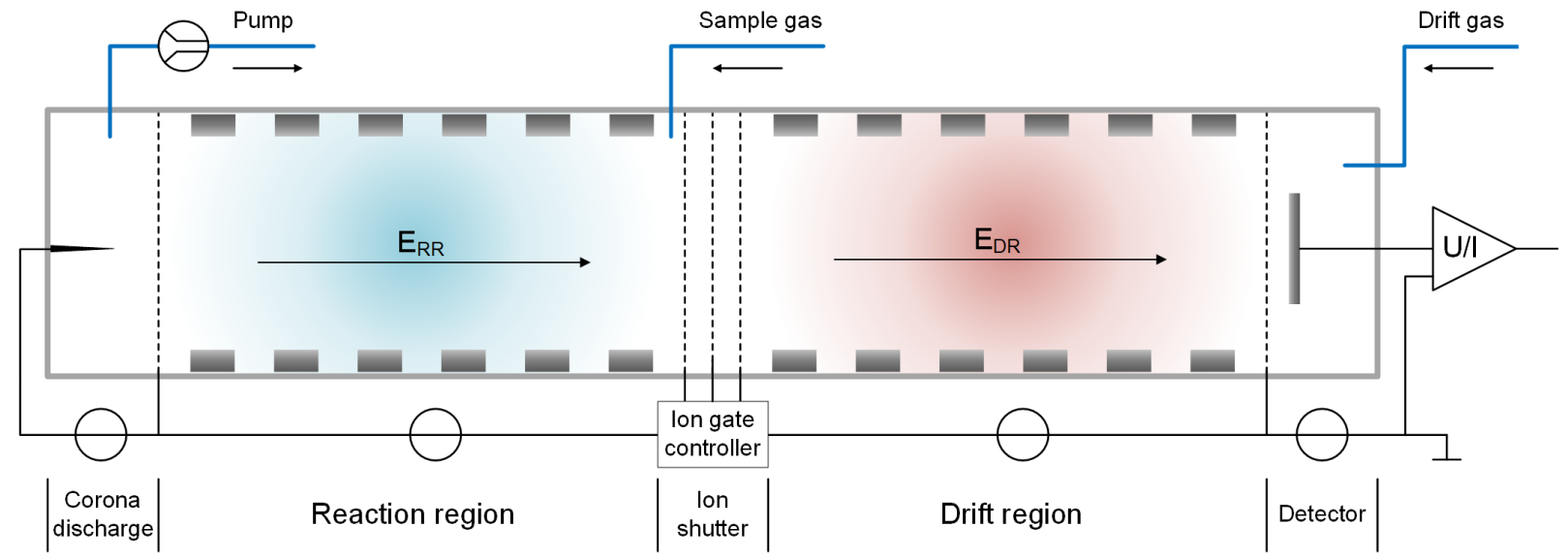

Figure 1: Schematic of the HiKE-IMS

Table 1: HiKE-IMS operating parameters.

${ }^{a} \mathrm{mls} / \mathrm{min}$ : milliliter standard per minute, mass flow at reference conditions $20^{\circ} \mathrm{C}$ and $1013.25 \mathrm{hPa}$

\begin{tabular}{l|l}
\hline Parameter & Value \\
\hline Temperature & $45^{\circ} \mathrm{C}$ \\
Pressure & $14.3 \mathrm{mbar}$ \\
Drift gas flow & $19 \mathrm{ml}_{\mathrm{s}} / \mathrm{min}^{\text {a }}$ \\
Sample gas flow & $19 \mathrm{ml}_{\mathrm{s}} / \mathrm{min}^{\text {a }}$ \\
Drift tube length & $306 \mathrm{~mm}$ \\
Reduced drift field & up to $100 \mathrm{Td}$ \\
Reaction tube length & $77 \mathrm{~mm}$ \\
Reduced reaction field & up to $100 \mathrm{Td}$ \\
CD voltage & $1100 \mathrm{~V}$ \\
CD current & $11 \mu \mathrm{A}$ \\
Injection time & $1 \mu \mathrm{s}$
\end{tabular}




\section{Corona discharge ionization source}

The HiKE-IMS is equipped with a stainless steel corona discharge needle from Agilent (corona needle $\mathrm{APCl}, \mathrm{G1947-20029)}$ with a needle diameter of $660 \mu \mathrm{m}$. The needle is mounted in a chamber containing the gas outlet. Due to the chosen pneumatic setup, the corona discharge ionization source is operated in the so-called reverse flow regime as described by Ross and Bell ${ }^{14}$. For all measurements presented in this work, flow rates of $19 \mathrm{ml}_{\mathrm{s}} / \mathrm{min}$ for the drift gas and $19 \mathrm{ml} / \mathrm{min}$ for the sample gas have been used. Thus, an overall reverse gas flow of $38 \mathrm{ml} / \mathrm{min}$ results to flush radicals and neutrals generated by the corona discharge from the reaction region.

A stainless steel grid with $80 \%$ optical transparency serves as counter electrode of the corona needle. The gap distance between corona tip and counter grid electrode is $2 \mathrm{~mm}$. Using an external series resistance of $100 \mathrm{MOhm}$, the applied corona discharge voltage of $1100 \mathrm{~V}$ results in an average corona discharge current of $11 \mu \mathrm{A}$.

\section{HiKE-IMS-MS coupling}

To identify individual ion species associated with certain peaks in the ion mobility spectrum, the previously presented coupling of a HiKE-IMS to a self-built time-of-flight mass spectrometer (TOF-MS) is used. A detailed description of the coupling is given elsewhere ${ }^{9}$. The coupling is realized by replacing the Faraday detector at the end of the HiKE-IMS drift region by a Faraday grid shielded by two aperture grids. A fast current amplifier (self-built, $150 \mathrm{kHz}$, gain $=3 \times 10^{8} \mathrm{~V} / \mathrm{A}{ }^{19}$ ) is connected to the Faraday grid for measuring the ion mobility spectrum at the end of the drift region. By varying the potential of the Faraday grid according to the tristate ion shutter mechanism ${ }^{3}$, this grid formation also serves as second ion gate allowing to transfer selected sections or peaks of the ion mobility spectrum into the MS (selected-mobility-mode). In this way, clear allocation of ion masses to a certain peak in the HiKE-IMS spectrum is possible.

\section{Gas supply}

As stated in the introduction, it has been shown that the negative ion population generated in air is strongly affected by the concentrations of carbon dioxide and water. In this work, purified air containing $<1 \mathrm{ppm}_{\vee}$ of water and $<1 \mathrm{ppm}_{\vee}$ of carbon dioxide is supplied by a zero air generator (JAG, JAGZAG600S) combined with a pressure swing absorber (PureGas, CAS1) in series with an additional moisture trap (Supelco, Molecular Sieve 5A Moisture Trap, 23991) and an activated carbon filter (Supelco, Supelcarb ${ }^{\circledR}$ HC Hydrocarbon Trap, 24564). The water concentration in the sample gas can independently be varied by mixing the supplied purified air with air that is passed through a water container. The resulting humidity of the sample and drift gas is measured by dew point sensors (Michell Instruments, Easidew Transmitter). Similarly, the carbon dioxide concentration in the sample and drift gas can be independently adjusted by mixing the supplied purified air with carbon dioxide from a gas cylinder (Linde AG, 5.3 purity). The resulting carbon dioxide concentration is calculated from the mixing ratio of the gases.

However, due to diffusion through seals and tubings, the residual water and carbon dioxide concentration in the HiKE-IMS may well exceed $1 \mathrm{ppm}_{\mathrm{v}}$. Thus, to ensure comparability of the results under different environmental conditions (temperature, ambient pressure, and humidity), the lowest water and carbon dioxide concentration in the sample and drift gas was intentionally increased to $70 \mathrm{ppm}_{\mathrm{v}}$ and $30 \mathrm{ppm}_{\mathrm{v}}$, respectively.

\section{Formation of negative reactant ions in HiKE-IMS}

In order to understand the formation of negative reactant ions in HiKE-IMS, several processes have to be taken into account. The following review is largely based on the work of Li et al. ${ }^{20}$. Similar kinetic 
schemes have been used by e.g. Zhao et al. ${ }^{21}$, Pancheshnyi ${ }^{22}$, Ponomarev and Aleksandrov ${ }^{23}$ as well as Haefliger et al. ${ }^{24}$.

In HiKE-IMS, the formation of negative reactant ions is initiated by free electrons generated in the negative corona discharge. When colliding with neutral molecules, these electrons may induce different processes depending on their kinetic energy. The distribution of kinetic energies of the electrons is determined by the applied reduced electric field and the background gas composition. Close to the corona tip, the reduced electric field strength is far above $100 \mathrm{Td}^{25}$. Entering the reaction region, the kinetic electron energy decreases. Here, the reduced electric field strength can be varied between $20 \mathrm{Td}$ and $100 \mathrm{Td}$.

In dry purified air (approx. $80 \% \mathrm{~N}_{2}$ and $20 \% \mathrm{O}_{2}$ ) containing neither water nor carbon dioxide residues, the formation of negative ions is initiated by electron attachment to the electron affine oxygen molecule (electron affinity of $0.43 \mathrm{eV}^{26}$ ). Since nitrogen molecules exhibit no electron affinity, they are of minor importance for the formation of negative ions.

At low electron energies, $\mathrm{O}_{2}^{-}$ions are generated in the three-body reaction (1) involving a neutral molecule $M$ to remove the excess energy ${ }^{27-29}$. The neutral molecule $M$ may be either $\mathrm{N}_{2}$ or $\mathrm{O}_{2}$.

$$
e^{-}+O_{2}+M \stackrel{k_{1}}{\rightarrow} O_{2}^{-}+M
$$

In contrast, at higher electron energies, mainly $\mathrm{O}^{-}$ions are formed by the dissociative electron attachment reaction (2) ${ }^{27,30,31}$, which is endothermic by $6.7 \mathrm{eV}^{28}$.

$$
e^{-}+\mathrm{O}_{2} \stackrel{k_{2}}{\rightarrow} \mathrm{O}^{-}+\mathrm{O}
$$

Figure 2 depicts the rate constants of reactions (1) and (2) as a function of the reduced electric field strength $E / N$. To enable the comparison of the termolecular rate constant $k_{1}$ with the bimolecular rate constant $k_{2}$, the termolecular rate constant $k_{1}$ is multiplied with the number density at the operating pressure of $14.3 \mathrm{mbar}\left(3.3 \cdot 10^{17} 1 / \mathrm{cm}^{3}\right)$ to gain a bimolecular rate constant $k_{1 b}$. According to the data in Figure 2, the three-body process (1) is dominant at reduced electric field strengths below $45 \mathrm{Td}$ while the dissociative electron attachment process (2) predominates in HiKE-IMS at reduced electric field strengths exceeding $45 \mathrm{Td}$.

After being captured by oxygen molecules, electrons may be released again through the detachment processes (3) and (4) ${ }^{30,32}$. Detachment process (3) is endothermic by $0.43 \mathrm{eV}$ and detachment process (4) is endothermic by $0.23 \mathrm{eV}^{33}$. Thus, as shown in Figure 2 , the rate constants $k_{3}$ and $k_{4}$ of these detachment processes increase with increasing reduced electric field strength.

$$
\begin{gathered}
\mathrm{O}_{2}^{-}+M \stackrel{k_{3}}{\rightarrow} \mathrm{O}_{2}+M+e^{-} \\
\mathrm{O}^{-}+\mathrm{N}_{2} \stackrel{k_{4}}{\rightarrow} N_{2} O+e^{-}
\end{gathered}
$$

Additionally, when colliding with oxygen molecules, the primary $\mathrm{O}^{-}$ion may undergo conversion reactions ${ }^{34,31,35}$. Ozone anions $\mathrm{O}_{3}{ }^{-}$may be formed in the three-body reaction (5). As reaction (5) is exothermic, a neutral molecule $M$ is required to remove the excess energy. Thus, increasing the reduced electric field strength, the rate constant $k_{5}$ decreases, see Figure 2 , where the reaction is represented by the bimolecular rate constant at the operating conditions $k_{5 b}$.

$$
\mathrm{O}^{-}+\mathrm{O}_{2}+\mathrm{M} \stackrel{k_{5}}{\rightarrow} \mathrm{O}_{3}^{-}+M
$$

Furthermore, $\mathrm{O}_{2}{ }^{-}$ions may be generated by the conversion reaction (6). Reaction (6) is endothermic by at least $0.6 \mathrm{eV}^{34}$. Nonetheless, at elevated reduced electric field strengths, the kinetic energy of the 
colliding ions may supply the energy deficit. Thus, as shown in Figure 2, at reduced electric field strengths exceeding $75 \mathrm{Td}$, the conversion reaction (6) is more likely than the three-body reaction (5).

$$
\mathrm{O}^{-}+\mathrm{O}_{2} \stackrel{k_{6}}{\rightarrow} \mathrm{O}_{2}^{-}+\mathrm{O}
$$

The occurring processes become more complex when water is added to the purified air. In addition to $\mathrm{O}^{-}$and $\mathrm{O}_{2}^{-}$ions, $\mathrm{H}^{-}$and $\mathrm{OH}^{-}$ions may be created by dissociative electron attachments to water molecules according to reactions (7) $-(9)^{20,23,36,17,37}$.

$$
\begin{aligned}
& e^{-}+\mathrm{H}_{2} \mathrm{O} \stackrel{k_{7}}{\rightarrow} \mathrm{O}^{-}+\mathrm{H}_{2} \\
& e^{-}+\mathrm{H}_{2} \mathrm{O} \stackrel{k_{8}}{\rightarrow} H^{-}+O H \\
& e^{-}+\mathrm{H}_{2} \mathrm{O} \stackrel{k_{9}}{\rightarrow} \mathrm{OH}^{-}+H
\end{aligned}
$$

Figure 2 depicts the rate constants $k_{7}, k_{8}$ and $k_{9}$ as a function of the reduced electric field strength $E / N$. Increasing the reduced electric field strength, the rate constants of these dissociative electron attachment processes increase.

In addition to the detachment processes (3) and (4), the processes (10) and (11) may occur in humid air ${ }^{20,23}$. Their rate constants $k_{10}$ and $k_{11}$ increase with increasing reduced electric field strength.

$$
\begin{gathered}
\mathrm{H}^{-}+\mathrm{O}_{2} \stackrel{k_{10}}{\longrightarrow} \mathrm{HO}_{2}+e^{-} \\
\mathrm{O}^{-}+\mathrm{H}_{2} \mathrm{O} \stackrel{k_{11}}{\longrightarrow} \mathrm{H}_{2} \mathrm{O}_{2}+e^{-}
\end{gathered}
$$

Furthermore, $\mathrm{O}^{-}$and $\mathrm{H}^{-}$ions may be converted to $\mathrm{OH}^{-}$ions according to reactions (12) and (13) ${ }^{23,20}$ when colliding with water.

$$
\begin{aligned}
& \mathrm{O}^{-}+\mathrm{H}_{2} \mathrm{O} \stackrel{k_{12}}{\longrightarrow} \mathrm{OH}^{-}+\mathrm{OH} \\
& \mathrm{H}^{-}+\mathrm{H}_{2} \mathrm{O} \stackrel{k_{13}}{\longrightarrow} \mathrm{OH}^{-}+\mathrm{H}_{2}
\end{aligned}
$$
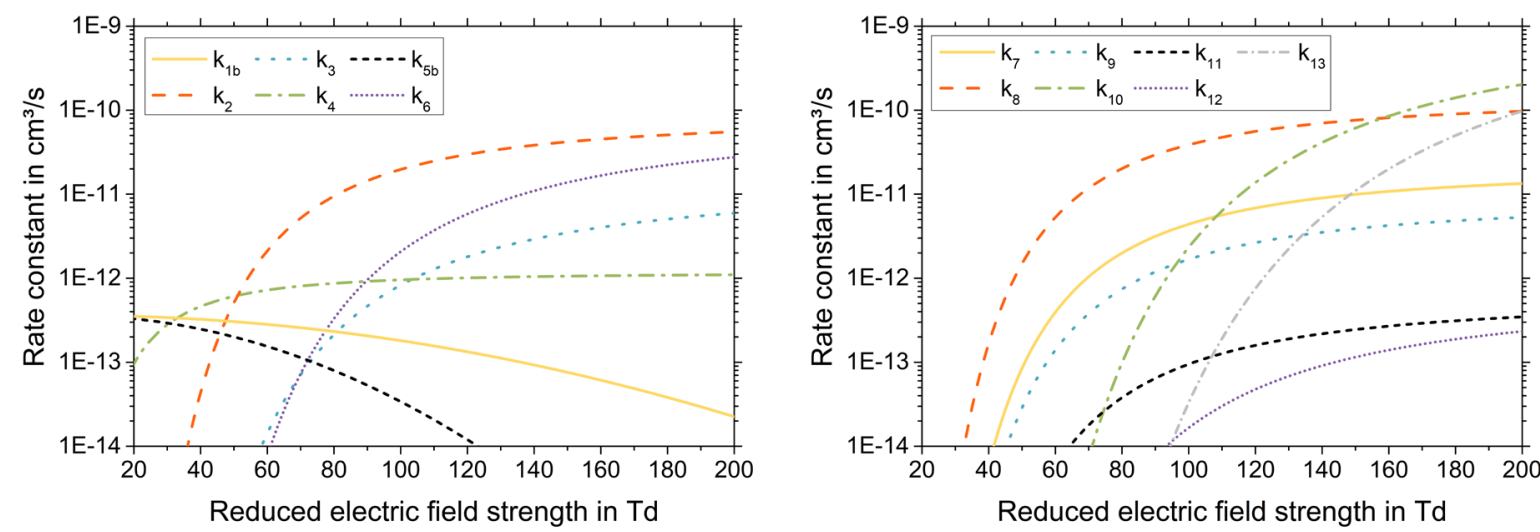

Figure 2: Rate constants $k_{1}-k_{13}$ of the attachment, detachment and conversion reactions (1) - (13) in air. The data are taken from the work of $L i$ et al. ${ }^{20}$ and Pancheshnyi ${ }^{22}$. For the three-body processes (1) and (5), the rate constants have been multiplied by the number density at 14.3 mbar to gain bimolecular rate constants $k_{1 b}$ and $k_{5 b}$. The underlying analytical expressions are listed in Table 2.

Additionally to the attachment, detachment and conversion reactions stated above, further reactions such as e.g. cluster association and dissociation reactions may proceed in the HiKE-IMS. As will be described below, the field-dependence of the rate constants of these reactions can be estimated using van't Hoff equations ${ }^{38}$ as well as the field-dependent effective ion temperature according to Wannier ${ }^{39}$. The corresponding thermodynamic and kinetic data are stated in Table 2 . However, we refrain from 
additionally plotting the resulting reaction rates as a function of the reduced electric field strength at this point.

In the presence of water, $\mathrm{O}^{-}$ions are converted to $\mathrm{OH}^{-}\left(\mathrm{H}_{2} \mathrm{O}\right)$ via the intermediate cluster $\mathrm{O}^{-}\left(\mathrm{H}_{2} \mathrm{O}\right)^{40}$ according to reactions (14) and (15).

$$
\begin{gathered}
\mathrm{O}^{-}+\mathrm{H}_{2} \mathrm{O}+\mathrm{M} \rightleftharpoons \mathrm{O}^{-}\left(\mathrm{H}_{2} \mathrm{O}\right)+\mathrm{M} \\
\mathrm{O}^{-}\left(\mathrm{H}_{2} \mathrm{O}\right)+\mathrm{H}_{2} \mathrm{O} \rightarrow \mathrm{OH}^{-}\left(\mathrm{H}_{2} \mathrm{O}\right)+\mathrm{OH}
\end{gathered}
$$

In contrast, $\mathrm{OH}^{-}, \mathrm{O}_{2}{ }^{-}$, and $\mathrm{O}_{3}{ }^{-}$ions form stable water clusters via the three-body processes (16) - (18) $41,13,16,42,40$.

$$
\begin{gathered}
O H^{-}\left(\mathrm{H}_{2} \mathrm{O}\right)_{n}+\mathrm{H}_{2} \mathrm{O}+\mathrm{M} \rightleftharpoons \mathrm{OH}^{-}\left(\mathrm{H}_{2} \mathrm{O}\right)_{n+1}+M \\
\mathrm{O}_{2}^{-}\left(\mathrm{H}_{2} \mathrm{O}\right)_{n}+\mathrm{H}_{2} \mathrm{O}+\mathrm{M} \rightleftharpoons \mathrm{O}_{2}^{-}{ }^{-}\left(\mathrm{H}_{2} \mathrm{O}\right)_{n+1}+M \\
\mathrm{O}_{3}{ }^{-}\left(\mathrm{H}_{2} \mathrm{O}\right)_{n}+\mathrm{H}_{2} \mathrm{O}+\mathrm{M} \rightleftharpoons \mathrm{O}_{3}^{-}\left(\mathrm{H}_{2} \mathrm{O}\right)_{n+1}+M
\end{gathered}
$$

Figure 3 shows a schematic overview of the processes in purified air containing water. In dependence on the reduced electric field strength and the water concentration, $\mathrm{O}^{-}\left(\mathrm{H}_{2} \mathrm{O}\right)_{n}, \mathrm{OH}^{-}\left(\mathrm{H}_{2} \mathrm{O}\right)_{n}, \mathrm{O}_{2}^{-}\left(\mathrm{H}_{2} \mathrm{O}\right)_{n}$ and $\mathrm{O}_{3}{ }^{-}\left(\mathrm{H}_{2} \mathrm{O}\right)_{n}$ are expected as primary ion species in the HiKE-IMS.

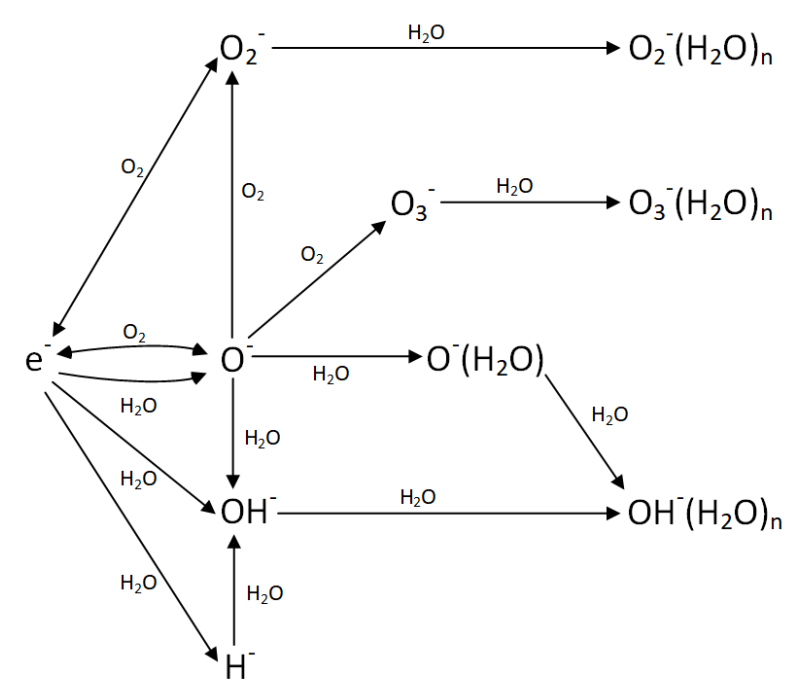

Figure 3: Simplified reaction scheme for the formation of negative reactant ions in air. Depending on the electron energy $E_{e-\text {, }}$ the attachment of the primary electron e- to $\mathrm{O}_{2}$ might result in either $\mathrm{O}^{-}$or $\mathrm{O}_{2}^{-}$. Furthermore, depending on the energy of $\mathrm{O}^{-}$, the collision of $\mathrm{O}^{-}$with $\mathrm{O}_{2}$ might result in either $\mathrm{O}_{2}^{-}$or $\mathrm{O}_{3}^{-}$.

However, the presence of $\mathrm{CO}_{2}$ may significantly influence the observed ion population in the HiKE-IMS. Since $\mathrm{CO}_{2}$ exhibits no electron affinity, direct charge transfer reactions involving $\mathrm{CO}_{2}$ are not possible. Nonetheless, the presence of $\mathrm{CO}_{2}$ results in the production of $\mathrm{CO}_{3}{ }_{3}, \mathrm{HCO}_{3}{ }^{-}$and/or $\mathrm{CO}_{4}{ }^{-}$ions by the threebody clustering processes (19) - (21) or by the exothermic switching reaction (22) ${ }^{13,40}$.

$$
\begin{aligned}
& \mathrm{O}^{-}+\mathrm{CO}_{2}+\mathrm{M} \rightleftharpoons \mathrm{CO}_{3}{ }^{-}+\mathrm{M} \\
& \mathrm{O}_{2}{ }^{-}+\mathrm{CO}_{2}+\mathrm{M} \rightleftharpoons \mathrm{CO}_{4}{ }^{-}+\mathrm{M} \\
& \mathrm{OH}^{-}+\mathrm{CO}_{2}+\mathrm{M} \rightleftharpoons \mathrm{HCO}_{3}{ }^{-}+\mathrm{M} \\
& \mathrm{O}_{3}{ }^{-}+\mathrm{CO}_{2} \rightarrow \mathrm{CO}_{3}{ }^{-}+\mathrm{O}_{2}
\end{aligned}
$$

In the presence of water, $\mathrm{CO}_{3}{ }^{-}$and $\mathrm{HCO}_{3}{ }^{-}$ions form stable water clusters via the three-body processes (23) and (24) ${ }^{43}$. 


$$
\begin{gathered}
\mathrm{CO}_{3}{ }^{-}\left(\mathrm{H}_{2} \mathrm{O}\right)_{n}+\mathrm{H}_{2} \mathrm{O}+\mathrm{M} \rightleftharpoons \mathrm{CO}_{3}{ }^{-}\left(\mathrm{H}_{2} \mathrm{O}\right)_{n+1}+\mathrm{M} \\
\mathrm{HCO}_{3}{ }^{-}\left(\mathrm{H}_{2} \mathrm{O}\right)_{n}+\mathrm{H}_{2} \mathrm{O}+\mathrm{M} \rightleftharpoons \mathrm{HCO}_{3}{ }^{-}\left(\mathrm{H}_{2} \mathrm{O}\right)_{n+1}+\mathrm{M}
\end{gathered}
$$

Furthermore, reactions (25) - (28) may occur ${ }^{13,44}$.

$$
\begin{gathered}
\mathrm{O}^{-}\left(\mathrm{H}_{2} \mathrm{O}\right)+\mathrm{CO}_{2} \rightarrow \mathrm{CO}_{3}^{-}+\mathrm{H}_{2} \mathrm{O} \\
\mathrm{O}_{2}^{-}\left(\mathrm{H}_{2} \mathrm{O}\right)_{n}+\mathrm{CO}_{2} \rightarrow \mathrm{CO}_{4}^{-}\left(\mathrm{H}_{2} \mathrm{O}\right)_{n-k}+k \cdot \mathrm{H}_{2} \mathrm{O} \quad(26) \\
\mathrm{OH}^{-}\left(\mathrm{H}_{2} \mathrm{O}\right)_{n}+\mathrm{CO}_{2} \rightarrow \mathrm{HCO}_{3}{ }^{-}\left(\mathrm{H}_{2} \mathrm{O}\right)_{n-k}+k \cdot \mathrm{H}_{2} \mathrm{O} \quad 1 \leq k \leq n \\
\mathrm{O}_{3}{ }^{-}\left(\mathrm{H}_{2} \mathrm{O}\right)_{n}+\mathrm{CO}_{2} \rightarrow \mathrm{CO}_{3}{ }^{-}\left(\mathrm{H}_{2} \mathrm{O}\right)_{n-k}+k \cdot \mathrm{H}_{2} \mathrm{O}+\mathrm{O}_{2} \quad 0 \leq k \leq n
\end{gathered}
$$

However, it is noteworthy that the rate constant of reactions (26) - (28) significantly decreases with increasing cluster size $n^{40,44}$.

Although the corona discharge ionization source in the HiKE-IMS is operated in reverse flow, residual amounts of the neutral discharge products $\mathrm{O}_{3}$ and $\mathrm{NO}_{x}$ may influence the observed ion population in the HiKE-IMS. Due to the high electron affinity of $2.1 \mathrm{eV}^{26}, \mathrm{O}_{3}$ can be ionized via direct charge transfer by $\mathrm{O}^{-}\left(\mathrm{H}_{2} \mathrm{O}\right)_{\mathrm{n}}, \mathrm{OH}^{-}\left(\mathrm{H}_{2} \mathrm{O}\right)_{\mathrm{n}}$ and $\mathrm{O}_{2}^{-}\left(\mathrm{H}_{2} \mathrm{O}\right)_{n}{ }^{16,45}$. Additionally, $\mathrm{CO}_{4}^{-}$reacts to $\mathrm{O}_{3}{ }^{-}$when colliding with $\mathrm{O}_{3}{ }^{14,40}$. In contrast, neither a reaction of $\mathrm{CO}_{3}{ }^{-}\left(\mathrm{H}_{2} \mathrm{O}\right)_{n}$ nor a reaction of $\mathrm{HCO}_{3}^{-}\left(\mathrm{H}_{2} \mathrm{O}\right)_{n}$ with $\mathrm{O}_{3}$ has been observed ${ }^{13}$.

$$
\begin{aligned}
\mathrm{O}^{-}\left(\mathrm{H}_{2} \mathrm{O}\right)_{n}+\mathrm{O}_{3} & \rightarrow \mathrm{O}_{3}{ }^{-}\left(\mathrm{H}_{2} \mathrm{O}\right)_{n-k}+\mathrm{O}+k \cdot \mathrm{H}_{2} \mathrm{O} \\
O \mathrm{H}^{-}\left(\mathrm{H}_{2} \mathrm{O}\right)_{n}+\mathrm{O}_{3} & \rightarrow \mathrm{O}_{3}{ }^{-}\left(\mathrm{H}_{2} \mathrm{O}\right)_{n-k}+\mathrm{OH}+k \cdot \mathrm{H}_{2} \mathrm{O} \\
\mathrm{O}_{2}{ }^{-}\left(\mathrm{H}_{2} \mathrm{O}\right)_{n}+\mathrm{O}_{3} & \rightarrow \mathrm{O}_{3}{ }^{-}\left(\mathrm{H}_{2} \mathrm{O}\right)_{n-k}+\mathrm{O}_{2}+k \cdot \mathrm{H}_{2} \mathrm{O} \\
\mathrm{CO}_{4}{ }^{-}+\mathrm{O}_{3} & \rightarrow \mathrm{O}_{3}{ }^{-}+\mathrm{CO}_{2}+\mathrm{O}_{2}
\end{aligned}
$$

Moreover, the neutral discharge products $\mathrm{NO}$ and $\mathrm{NO}_{2}$ may undergo several reactions resulting in $\mathrm{NO}_{2}^{-}\left(\mathrm{H}_{2} \mathrm{O}\right)_{n}$ or $\mathrm{NO}_{3}^{-}\left(\mathrm{H}_{2} \mathrm{O}\right)_{n}$ ions ${ }^{40,13,46,16}$. However, according to the experimental results, nitrogen oxides seem to be of minor importance in the HiKE-IMS.

In order to kinetically model the formation of negative ions in the HiKE-IMS, reactions (1) - (32) and their corresponding reaction rate constants can be expressed by a system of ordinary differential equations. Since the neutral reaction partners are present in vast excess, all reactions are considered to be pseudo-first order with respect to the ionic species. The numerical solution of the resulting differential equation system provides the concentration of each ionic species as a function of time. In this work, the differential equation system is solved using the MATLAB function "ode45" which implements a Runge-Kutta $(4,5)$ integration scheme.

To include the influence of the reduced electric field strength, the forward rate constants of the attachment, detachment and conversion processes (1) - (13) are assumed to be field-dependent according to the curves plotted in Figure 2. Furthermore, the field-dependence of the water cluster formation and dissociation equilibria (14), (16), (17), (18), (23) and (24) is included in the model by calculating field-dependent cluster dissociation rate constants. As presented in detail in a previous work ${ }^{10}$, using van't Hoff equations ${ }^{38}$, the field-dependence of the cluster dissociation rate constants can be estimated from the rate constant of the cluster association reaction at $300 \mathrm{~K}$, its molar standard reaction enthalpy, its molar standard reaction entropy as well as the field-dependent effective ion temperature according to Wannier ${ }^{39}$. In addition to the field-dependence of the water cluster equilibria (14), (16), (17), (18), (23) and (24), the field-dependence of the equilibria (5), (19), (20) and (21) of the clusters $\mathrm{O}_{3}^{-}\left(=\mathrm{O}^{-} . \mathrm{O}_{2}\right), \mathrm{CO}_{3}^{-}\left(=\mathrm{O}^{-} \cdot \mathrm{CO}_{2}\right), \mathrm{CO}_{4}^{-}\left(=\mathrm{O}_{2}^{-} \cdot \mathrm{CO}_{2}\right)$ and $\mathrm{HCO}_{3}^{-}\left(=\mathrm{OH}^{-} . \mathrm{CO}_{2}\right)$ may be taken into account. However, the dissociation enthalpies of $\mathrm{O}_{3}^{-}\left(43 \mathrm{kcal} / \mathrm{mol}^{47}\right), \mathrm{CO}_{3}{ }^{-}\left(47,8 \mathrm{kcal} / \mathrm{mol}^{26}\right)$ and $\mathrm{HCO}_{3}{ }^{-}\left(88 \mathrm{kcal} / \mathrm{mol}^{48}\right)$ are very high. Thus, the dissociation of these clusters is of minor relevance at 
reduced electric field strength between $20 \mathrm{Td}$ and $100 \mathrm{Td}^{45}$ and neglected in this work. Nonetheless, the dissociation enthalpy of $\mathrm{CO}_{4}^{-}\left(19 \mathrm{kcal} / \mathrm{mol}^{49}\right)$ is comparably low. Hence, the dissociation of $\mathrm{CO}_{4}{ }^{-}$is included in the model. The rate constants of the simple bimolecular charge transfer reactions (15), (22), (25) - (32) are assumed to be field-independent.

In Table 2, the thermodynamic and kinetic data used in the kinetic model are summarized. Based on these data, the negative reactant ion population at the end of the reaction region of the HiKE-IMS is modeled. It is noteworthy that the processes occurring during corona discharge are obviously more complex than those stated above. In particular under the influence of the high electric field in close vicinity to the corona tip, electrons may also initiate ionization, dissociation or excitation processes 37,50,51 leading to the generation of e.g. the neutral discharge products $\mathrm{O}_{3}$ and $\mathrm{NO}_{x}$. However, a complete description of all these processes would exceed the scope of this work. Instead, the following simplified boundary conditions are assumed to model the negative reactant ion population in HiKEIMS:

1) The ozone concentration in the reaction region of the HiKE-IMS is unknown. The generation of ozone in corona discharges depends on various parameters such as the corona discharge current ${ }^{52,53}$, the temperature ${ }^{54}$, the geometry of corona needle and counter electrode ${ }^{52,53}$, the background gas composition ${ }^{55,56}$ and the gas flow ${ }^{54,14}$. Thus, the ozone concentrations reported in the literature range from hundreds of $\mathrm{ppb}_{\mathrm{v}}$ to a few $\%_{\mathrm{v}}{ }^{14,53,55,13}$. In accordance with the experimental results, we assume a constant $\mathrm{O}_{3}$ background concentration of $120 \mathrm{ppm}_{\mathrm{v}}$ in the reaction region of the HiKE-IMS in this model.

2) As the residence time of electrons in the discharge gap of $2 \mathrm{~mm}$ length is negligibly small compared to the residence time of electrons in the reaction region of $77 \mathrm{~mm}$ length, any reactions that might occur inside the discharge gap are neglected in the model. The simulation starts with electrons being injected into the reaction region. These electrons traverse the reaction region under the influence of the electric field and generate primary ions, which in turn undergo various reactions with neutral molecules.

3) To model the negative reactant ion population at the end of the reaction region, the $77 \mathrm{~mm}$ long reaction region is divided into 77 segments of $1 \mathrm{~mm}$ length. In the first step, the time required by the electrons to cross the first segment is calculated from the electron drift velocity ${ }^{57}$. Subsequently, the kinetic model described above is used to estimate the ion population generated by the electrons during this time. In the second step, the remaining electrons and the generated ion population cross the second segment. The times required by every individual ion species to cross the second segment are calculated from their reduced ion mobilities. Again, these times are used in the kinetic model to estimate the conversion of the respective ion species during traversing the second segment. In the third step, the remaining electrons and the overall ion population resulting from the conversion processes in the second part cross the third part, and so on.

In the next section, the results predicted by this model are compared with experimental results. It is shown that these assumptions allow a qualitative prediction of the processes in HiKE-IMS. 
Table 2: Thermodynamic and kinetic data used in this work to model the negative reactant ion formation mechanisms in the HiKE-IMS. The listed data are determined at $\sim 300 \mathrm{~K}$. The stated reduced ion mobilities $K_{0}$ are estimated from the mass of the ions as presented by Appelhans et al. ${ }^{58}$ and used in a previous work ${ }^{10}$. The field-dependence of the reduced ion mobility is neglected.

\begin{tabular}{|c|c|c|c|c|c|}
\hline & Reaction & $\begin{array}{l}\text { Forward rate constant } \\
\text { in } \frac{\mathrm{cm}^{3}}{s} \text { or } \frac{\mathrm{cm}^{6}}{s} \text { (as a function of } \\
\mathrm{E} / \mathrm{N} \text { in Td) }\end{array}$ & $\begin{array}{l}\Delta_{R} H \text { in } \\
\mathrm{kcal} \mathrm{mol}^{-1}\end{array}$ & $\begin{array}{l}\Delta_{R} S \text { in } \\
\text { cal mol }^{-1} \\
\mathrm{~K}^{-1}\end{array}$ & $\begin{array}{l}\mathrm{K}_{0} \text { of } \\
\text { product ion } \\
\text { in } \mathrm{cm}^{2} / \mathrm{Vs}\end{array}$ \\
\hline 1 & $\begin{array}{c}e^{-}+O_{2}+M \rightarrow \\
O_{2}^{-}+M\end{array}$ & $1.1 \cdot 10^{-30} \cdot e^{\left(-\left(\frac{E / N}{120}\right)^{2}\right)} \quad 20$ & & & \\
\hline 2 & $\begin{array}{l}e^{-}+O_{2} \rightarrow \\
O^{-}+O\end{array}$ & $8 \cdot 10^{-11} \cdot e^{\left(-\left(\frac{125}{5.6+E / N}\right)^{2}\right)} \quad 20$ & & & \\
\hline 3 & $\begin{array}{l}O_{2}^{-}+M \rightarrow \\
O_{2}+M+e^{-}\end{array}$ & $1.24 \cdot 10^{-11} \cdot e^{\left(-\left(\frac{179}{8.8+E / N}\right)^{2}\right)} \quad 22$ & & & \\
\hline 4 & $\begin{array}{l}\mathrm{O}^{-}+\mathrm{N}_{2} \rightarrow \\
\mathrm{N}_{2} \mathrm{O}+e^{-}\end{array}$ & $1.16 \cdot 10^{-12} \cdot e^{\left(-\left(\frac{48.9}{11+E / N}\right)^{2}\right)} \quad 22$ & & & \\
\hline 5 & $\begin{array}{c}\mathrm{O}^{-}+\mathrm{O}_{2}+M \rightarrow \\
\mathrm{O}_{3}^{-}+M\end{array}$ & $1.1 \cdot 10^{-30} \cdot e^{\left(-\left(\frac{E / N}{65}\right)^{2}\right)} \quad 22$ & $-43 \quad 47$ & & \\
\hline 6 & $\begin{array}{c}\mathrm{O}^{-}+\mathrm{O}_{2} \rightarrow \\
\mathrm{O}_{2}^{-}+\mathrm{O}\end{array}$ & $6.96 \cdot 10^{-11} \cdot e^{\left(-\left(\frac{198}{5.6+E / N}\right)^{2}\right)} \quad 22$ & & & \\
\hline 7 & $\begin{array}{c}e^{-}+\mathrm{H}_{2} \mathrm{O} \rightarrow \\
\mathrm{O}^{-}+\mathrm{H}_{2}\end{array}$ & $2 \cdot 10^{-11} \cdot e^{\left(-\left(\frac{130}{5.6+E / N}\right)^{2}\right)} \quad 20$ & & & \\
\hline 8 & $\begin{array}{c}e^{-}+\mathrm{H}_{2} \mathrm{O} \rightarrow \\
H^{-}+O H\end{array}$ & $1.35 \cdot 10^{-10} \cdot e^{\left(-\left(\frac{118}{5.6+E / N}\right)^{2}\right)} \quad 20$ & & & \\
\hline 9 & $\begin{array}{l}e^{-}+\mathrm{H}_{2} \mathrm{O} \rightarrow \\
O \mathrm{H}^{-}+\mathrm{H}\end{array}$ & $8 \cdot 10^{-12} \cdot e^{\left(-\left(\frac{132}{5.6+E / N}\right)^{2}\right)} \quad 20$ & & & \\
\hline 10 & $\begin{array}{l}\mathrm{H}^{-}+\mathrm{O}_{2} \rightarrow \\
\mathrm{HO}_{2}+e^{-}\end{array}$ & $1 \cdot 10^{-9} \cdot e^{\left(-\left(\frac{260}{5.6+E / N}\right)^{2}\right)} \quad 20$ & & & \\
\hline 11 & $\begin{array}{l}\mathrm{O}^{-}+\mathrm{H}_{2} \mathrm{O} \rightarrow \\
\mathrm{H}_{2} \mathrm{O}_{2}+e^{-}\end{array}$ & $5.5 \cdot 10^{-13} \cdot e^{\left(-\left(\frac{140}{5.6+E / N}\right)^{2}\right)} \quad 20$ & & & \\
\hline 12 & $\begin{array}{l}\mathrm{O}^{-}+\mathrm{H}_{2} \mathrm{O} \rightarrow \\
\mathrm{OH}^{-}+\mathrm{OH}\end{array}$ & $6 \cdot 10^{-13} \cdot e^{\left(-\left(\frac{200}{5.6+E / N}\right)^{2}\right)} \quad 20$ & & & \\
\hline 13 & $\begin{array}{c}\mathrm{H}^{-}+\mathrm{H}_{2} \mathrm{O} \rightarrow \\
\mathrm{OH}^{-}+\mathrm{H}_{2}\end{array}$ & $2 \cdot 10^{-9} \cdot e^{\left(-\left(\frac{365}{10+E / N}\right)^{2}\right)} \quad 20$ & & & \\
\hline 14 & $\begin{array}{c}\mathrm{O}^{-}+\mathrm{H}_{2} \mathrm{O}+\mathrm{M} \rightleftharpoons \\
\mathrm{O}^{-}\left(\mathrm{H}_{2} \mathrm{O}\right)+M\end{array}$ & $1.3 \cdot 10^{-28} \quad 40$ & $-31 \quad 40$ & -20 & 2.85 \\
\hline 15 & $\begin{array}{c}\mathrm{O}^{-}\left(\mathrm{H}_{2} \mathrm{O}\right)+\mathrm{H}_{2} \mathrm{O} \rightarrow \\
\mathrm{OH}^{-}\left(\mathrm{H}_{2} \mathrm{O}\right)+\mathrm{OH}\end{array}$ & $1 \cdot 10^{-11} \quad 40$ & & & \\
\hline $16 a$ & $\begin{array}{c}\mathrm{OH}^{-}+\mathrm{H}_{2} \mathrm{O}+\mathrm{M} \rightleftharpoons \\
\mathrm{OH}^{-}\left(\mathrm{H}_{2} \mathrm{O}\right)+\mathrm{M}\end{array}$ & $2.5 \cdot 10^{-28} \quad 40$ & $-22.5 \quad 41$ & $\begin{array}{l}-19.1 \\
41\end{array}$ & 2.82 \\
\hline
\end{tabular}




\begin{tabular}{|c|c|c|c|c|c|c|}
\hline $16 b$ & $\begin{array}{c}\mathrm{OH}^{-}\left(\mathrm{H}_{2} \mathrm{O}\right)+\mathrm{H}_{2} \mathrm{O}+\mathrm{M} \rightleftharpoons \\
O \mathrm{H}^{-}\left(\mathrm{H}_{2} \mathrm{O}\right)_{2}+M\end{array}$ & $3.5 \cdot 10^{-28}$ & 40 & $-16.4 \quad 41$ & $\begin{array}{l}-19.3 \\
41\end{array}$ & 2.38 \\
\hline $17 a$ & $\begin{array}{c}\mathrm{O}_{2}^{-}+\mathrm{H}_{2} \mathrm{O}+\mathrm{M} \rightleftharpoons \\
\mathrm{O}_{2}{ }^{-}\left(\mathrm{H}_{2} \mathrm{O}\right)+M\end{array}$ & $1.6 \cdot 10^{-28}$ & 42 & $-18.4 \quad 41$ & $\begin{array}{l}-20.1 \\
41\end{array}$ & 2.44 \\
\hline $17 b$ & $\begin{array}{c}\mathrm{O}_{2}^{-}\left(\mathrm{H}_{2} \mathrm{O}\right)+\mathrm{H}_{2} \mathrm{O}+\mathrm{M} \rightleftharpoons \\
\mathrm{O}_{2}^{-}\left(\mathrm{H}_{2} \mathrm{O}\right)_{2}+M\end{array}$ & $5.4 \cdot 10^{-28}$ & 42 & $-17.2 \quad 41$ & $\begin{array}{l}-25.1 \\
41\end{array}$ & 2.15 \\
\hline 18a & $\begin{array}{c}\mathrm{O}_{3}^{-}+\mathrm{H}_{2} \mathrm{O}+\mathrm{M} \rightleftharpoons \\
\mathrm{O}_{3}{ }^{-}\left(\mathrm{H}_{2} \mathrm{O}\right)+M\end{array}$ & $2.7 \cdot 10^{-28}$ & 40 & -18.7 & $\begin{array}{l}-23.8 \\
59\end{array}$ & 2.17 \\
\hline $18 b$ & $\begin{array}{c}\mathrm{O}_{3}^{-}\left(\mathrm{H}_{2} \mathrm{O}\right)+\mathrm{H}_{2} \mathrm{O}+\mathrm{M} \rightleftharpoons \\
\mathrm{O}_{3}^{-}\left(\mathrm{H}_{2} \mathrm{O}\right)_{2}+M\end{array}$ & $3 \cdot 10^{-28}$ & & $-15.2 \quad 59$ & $\begin{array}{l}-31.8 \\
59\end{array}$ & 1.96 \\
\hline 19 & $\begin{array}{c}\mathrm{O}^{-}+\mathrm{CO}_{2}+\mathrm{M} \rightleftharpoons \\
\mathrm{CO}_{3}^{-}+\mathrm{M}\end{array}$ & $3.1 \cdot 10^{-28}$ & 40 & $-47.8 \quad 26$ & & \\
\hline 20 & $\begin{array}{c}\mathrm{O}_{2}^{-}+\mathrm{CO}_{2}+\mathrm{M} \rightleftharpoons \\
\mathrm{CO}_{4}^{-}+M\end{array}$ & $4.7 \cdot 10^{-29}$ & 40 & -19 & $\begin{array}{ll}-24 & 49\end{array}$ & 2.05 \\
\hline 21 & $\begin{array}{c}\mathrm{OH}^{-}+\mathrm{CO}_{2}+\mathrm{M} \rightleftharpoons \\
\mathrm{HCO}_{3}^{-}+M\end{array}$ & $7.6 \cdot 10^{-28}$ & 40 & -88 & & \\
\hline 22 & $\begin{array}{c}\mathrm{O}_{3}^{-}+\mathrm{CO}_{2} \rightarrow \\
\mathrm{CO}_{3}^{-}+\mathrm{O}_{2}\end{array}$ & $4 \cdot 10^{-10}$ & & & & \\
\hline 23 & $\begin{array}{c}\mathrm{CO}_{3}^{-}+\mathrm{H}_{2} \mathrm{O}+\mathrm{M} \rightleftharpoons \\
\mathrm{CO}_{3}{ }^{-}\left(\mathrm{H}_{2} \mathrm{O}\right)+M\end{array}$ & $1 \cdot 10^{-28}$ & & -14.1 & $\begin{array}{l}-25.2 \\
43\end{array}$ & 2.02 \\
\hline 24 & $\begin{array}{c}\mathrm{HCO}_{3}^{-}+\mathrm{H}_{2} \mathrm{O}+\mathrm{M} \rightleftharpoons \\
\mathrm{HCO}_{3}{ }^{-}\left(\mathrm{H}_{2} \mathrm{O}\right)+M\end{array}$ & $1 \cdot 10^{-28}$ & & -15.7 & $\begin{array}{l}-24.1 \\
43\end{array}$ & 2.017 \\
\hline 25 & $\begin{array}{c}\mathrm{O}^{-}\left(\mathrm{H}_{2} \mathrm{O}\right)+\mathrm{CO}_{2} \\
\mathrm{CO}_{3}^{-}+\mathrm{H}_{2} \mathrm{O}\end{array}$ & $1 \cdot 10^{-10}$ & & & & \\
\hline 26 & $\begin{array}{c}\mathrm{O}_{2}^{-}\left(\mathrm{H}_{2} \mathrm{O}\right)+\mathrm{CO}_{2} \rightarrow \\
\mathrm{CO}_{4}^{-}+\mathrm{H}_{2} \mathrm{O}\end{array}$ & $5.2 \cdot 10^{-10}$ & & & & \\
\hline $27 a$ & $\begin{array}{c}\mathrm{OH}^{-}\left(\mathrm{H}_{2} \mathrm{O}\right)+\mathrm{CO}_{2} \rightarrow \\
\mathrm{HCO}_{3}^{-}+\mathrm{H}_{2} \mathrm{O}\end{array}$ & $6 \cdot 10^{-10}$ & & & & \\
\hline $27 b$ & $\begin{array}{l}\mathrm{OH}^{-}\left(\mathrm{H}_{2} \mathrm{O}\right)_{2}+\mathrm{CO}_{2} \rightarrow \\
\mathrm{HCO}_{3}^{-}\left(\mathrm{H}_{2} \mathrm{O}\right)+\mathrm{H}_{2} \mathrm{O}\end{array}$ & $6 \cdot 10^{-10}$ & & & & \\
\hline $28 a$ & $\begin{array}{c}\mathrm{O}_{3}^{-}\left(\mathrm{H}_{2} \mathrm{O}\right)+\mathrm{CO}_{2} \rightarrow \\
\mathrm{CO}_{3}^{-}+\mathrm{H}_{2} \mathrm{O}+\mathrm{O}_{2}\end{array}$ & $3.5 \cdot 10^{-10}$ & 40 & & & \\
\hline $28 \mathrm{~b}$ & $\begin{array}{c}\mathrm{O}_{3}^{-}\left(\mathrm{H}_{2} \mathrm{O}\right)_{2}+\mathrm{CO}_{2} \rightarrow \\
\mathrm{CO}_{3}^{-}\left(\mathrm{H}_{2} \mathrm{O}\right)+\mathrm{H}_{2} \mathrm{O}+\mathrm{O}_{2}\end{array}$ & $1 \cdot 10^{-10}$ & & & & \\
\hline $29 a$ & $\begin{array}{c}\mathrm{O}^{-}+\mathrm{O}_{3} \rightarrow \\
\mathrm{O}_{3}^{-}+\mathrm{O}\end{array}$ & $5.3 \cdot 10^{-10}$ & 13 & & & \\
\hline $29 \mathrm{~b}$ & $\begin{array}{l}\mathrm{O}^{-}\left(\mathrm{H}_{2} \mathrm{O}\right)+\mathrm{O}_{3} \rightarrow \\
\mathrm{O}_{3}^{-}+\mathrm{O}+\mathrm{H}_{2} \mathrm{O}\end{array}$ & $5.3 \cdot 10^{-10}$ & & & & \\
\hline
\end{tabular}




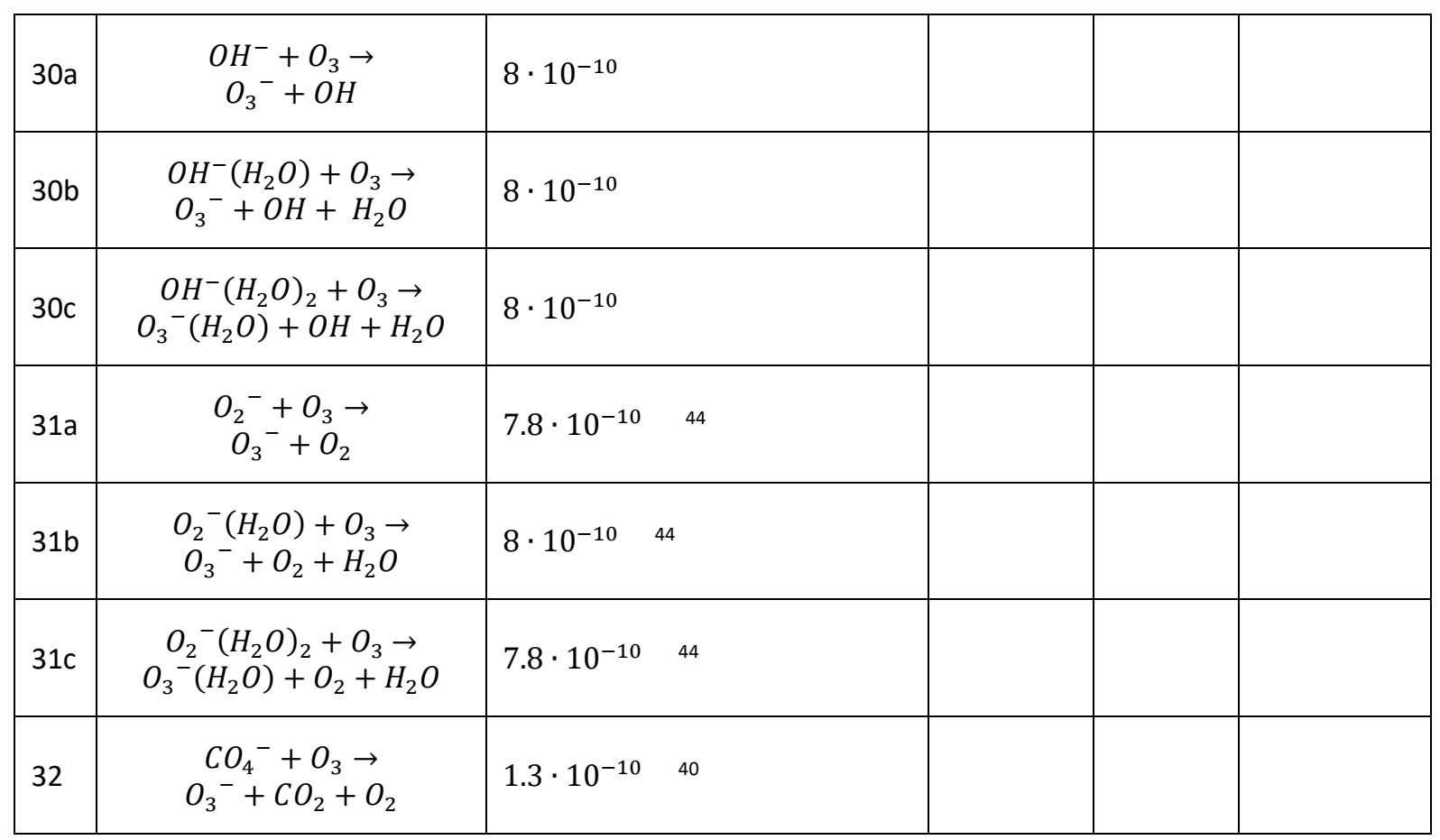

\section{Results and discussion}

In order to experimentally investigate the negative reactant ion population formed at the end of the reaction region, it is necessary to suppress reactions in the drift region, which alter the ion population. Thus, the $\mathrm{H}_{2} \mathrm{O}$ and $\mathrm{CO}_{2}$ concentrations in the drift gas are kept constant at the minimum concentrations of $70 \mathrm{ppm}_{\mathrm{v}}$ and $30 \mathrm{ppm}_{\mathrm{v}}$, respectively. Furthermore, the reduced electric field strength in the drift region is set to a constant value of $80 \mathrm{Td}$ in the present experiments. Under these conditions, the formation of water clusters and thus conversion reactions initiated by $\mathrm{H}_{2} \mathrm{O}$ should be mostly inhibited in the drift region. However, other conversion reactions in the drift region cannot be avoided. For example, electrons entering the drift region may attach to neutrals inside the drift region. Furthermore, $\mathrm{O}^{-}$ions are not stable. If these ions are injected into the drift region, they will convert to $\mathrm{O}_{2}{ }^{-}$or $\mathrm{O}_{3}{ }^{-}$while traversing the drift region. Finally, conversion reactions in the drift region initiated by residual amounts of $\mathrm{CO}_{2}$ cannot be inhibited entirely.

In the following, negative reactant ions in HiKE-IMS are identified by the previously introduced HiKEIMS-MS method ${ }^{9}$. Their abundances are subsequently analyzed in dependence on the reduced electric field strength as well as on the $\mathrm{H}_{2} \mathrm{O}$ and $\mathrm{CO}_{2}$ concentration in the reaction region. Furthermore, the experimental results are compared with the theoretical predictions of the kinetic model.

\section{Analysis of the HiKE-IMS spectrum at $100 \mathrm{Td}, 70 \mathrm{ppm}_{v} \underline{\mathrm{H}}_{2} \mathrm{O}$ and $30 \mathrm{ppm}_{v} \mathrm{CO}_{2}$}

At a reduced electric reaction field strength of $100 \mathrm{Td}$ as well as a background water concentration of $70 \mathrm{ppm}_{\mathrm{v}}$ and a background carbon dioxide concentration of $30 \mathrm{ppm}_{\mathrm{v}}$, the kinetic model presented in the previous section predicts that the negative ion population generated in the reaction region is composed of $53 \mathrm{\%} \mathrm{O}_{3}{ }^{-}, 27 \% \mathrm{O}^{-}, 12 \mathrm{\%} \mathrm{CO}_{3}{ }^{-}$and $8 \% \mathrm{O}_{2}{ }^{-}$. Furthermore, the model predicts that only $19 \%$ of the electrons injected into the reaction region attach to neutrals while traversing the reaction region. Hence, opening the ion shutter, it is likely that besides ions also electrons are injected into the drift region. The drift time of electrons at the reduced electric drift field strength of $80 \mathrm{Td}$ is about 850 ns. However, the first microseconds of the HiKE-IMS spectrum are interfered by electrical crosstalks due to the ion shutter pulse. Thus, it is not possible to observe an electron peak in the HiKEIMS spectrum. 
Figure 4a depicts the experimentally recorded HiKE-IMS spectrum at a reduced electric reaction field strength of $100 \mathrm{Td}$ as well as at $\mathrm{H}_{2} \mathrm{O}$ and $\mathrm{CO}_{2}$ concentrations in reaction region of $70 \mathrm{ppm}_{\mathrm{v}}$ and $30 \mathrm{ppm}_{\mathrm{v}}$, respectively. In the spectrum, five distinct peaks occur. Furthermore, a raise of the baseline between the drift times $\mathrm{t}=0 \mathrm{~s}$ and $\mathrm{t}=540 \mu \mathrm{s}$ is observed. To identify the individual ion species underlying the ion mobility spectrum, the sections marked in Figure 4a are successively transferred to a custom built time-of-flight mass spectrometer (TOF-MS) using a simple gated interface as described in detail in ${ }^{9}$. In this way, clear allocation of ion masses to a certain peaks or section in the HiKE-IMS spectrum is possible. In Figure $4 \mathrm{~b}$, the recorded mass spectra corresponding to the marked sections are shown.

As expected, we do not observe any signals in the mass spectrum when transferring section $b$ of the ion mobility spectrum into the mass spectrometer. However, investigating the raised baseline in section a, signals at $m / z=32$ and $m / z=48$ occur in the mass spectrum. These signals are related to the oxygen anion $\mathrm{O}_{2}{ }^{-}(32 \mathrm{u})$ and the ozone anion $\mathrm{O}_{3}{ }^{-}(48 \mathrm{u})$. As the theoretical model predicts the injection of considerable amounts of electrons and $\mathrm{O}^{-}$ions in the drift region, we assume that the observed oxygen anions $\mathrm{O}_{2}{ }^{-}$and ozone anions $\mathrm{O}_{3}{ }^{-}$result from reactions inside the drift region initiated by electrons or $\mathrm{O}^{-}$ions. While traversing the drift region at the reduced electric drift field strength of $80 \mathrm{Td}$, electrons may attach to oxygen according to reaction $\left(2^{\prime}\right)$ and thus generate $\mathrm{O}^{-}$ions at random positions in the drift region.

$$
e^{-}+O_{2} \rightarrow O^{-}+O
$$

The $\mathrm{O}^{-}$ions generated in the drift region by electrons and the $\mathrm{O}^{-}$ions injected directly into the drift region in turn undergo conversion reactions $\left(5^{\prime}\right)$ and $\left(6^{\prime}\right)$ while traversing the drift region resulting in the observed $\mathrm{O}_{2}{ }^{-}$and $\mathrm{O}_{3}{ }^{-}$ions.

$$
\begin{gathered}
\mathrm{O}^{-}+\mathrm{O}_{2}+\mathrm{M} \rightarrow \mathrm{O}_{3}{ }^{-}+\mathrm{M} \\
\mathrm{O}^{-}+\mathrm{O}_{2} \rightarrow \mathrm{O}_{2}{ }^{-}+\mathrm{O}
\end{gathered}
$$

As the generated oxygen anions $\mathrm{O}_{2}{ }^{-}$and ozone anions $\mathrm{O}_{3}{ }^{-}$reach the detector according to their random point of origin and their ion mobility, the baseline is expected to be raised. 


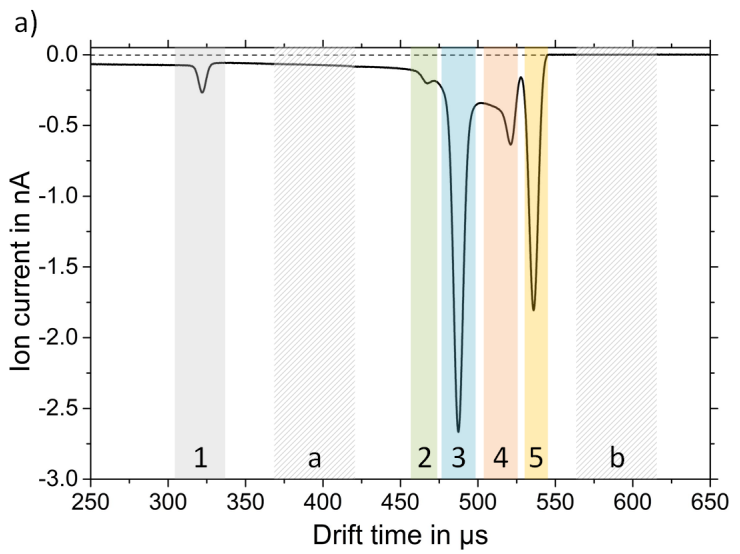

b) Baseline:
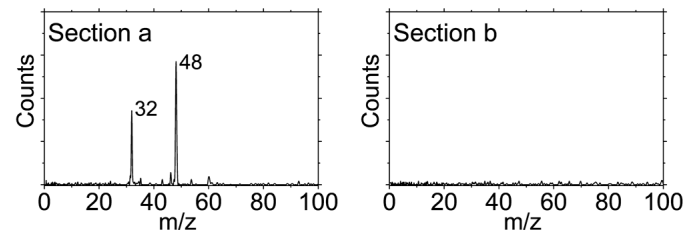

Peaks:
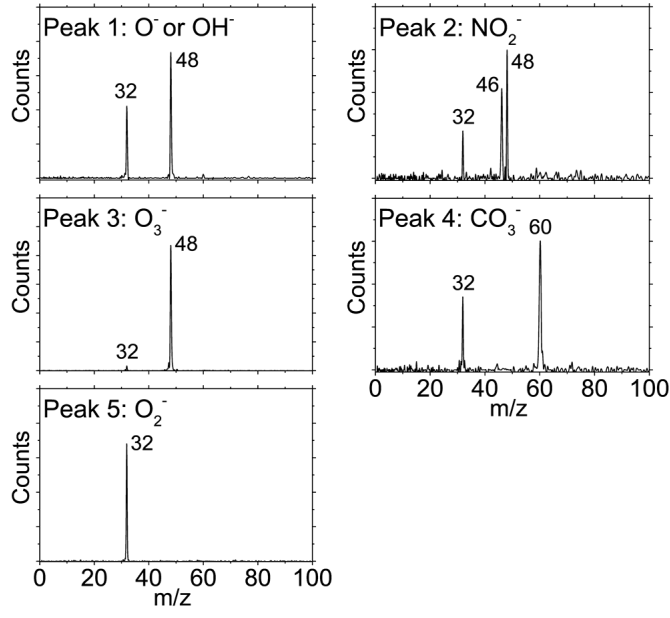

Figure 4: a) Recorded negative HiKE-IMS spectrum of purified air at constant reduced electric reaction field strength of 100 Td and constant reduced electric drift field strength of $80 \mathrm{Td}$, the $\mathrm{H}_{2} \mathrm{O}$ and $\mathrm{CO}_{2}$ concentrations in reaction and drift region are $70 \mathrm{ppm}_{v}$ and $30 \mathrm{ppm}_{v}$, respectively. The pressure is $14.3 \mathrm{mbar}$, the temperature is $45^{\circ} \mathrm{C}$, b) Mass spectra corresponding to the marked sections in the HiKE-IMS spectrum recorded by the HiKE-IMS-MS coupling operated in the selected-mobility-mode.

With this effect in mind, the ion species associated with the distinct peaks in the ion mobility spectrum can be identified. Due to the electron and $\mathrm{O}^{-}$driven generation of ion species in the drift region, every mass spectrum consists of mass signals that can be allocated to the selected peak and additional mass signals related to the background ion species. Based on the recorded mass spectra, peak 3 and 5 are identified as $\mathrm{O}_{3}^{-}(\mathrm{m} / \mathrm{z}=48)$ and $\mathrm{O}_{2}^{-}(\mathrm{m} / \mathrm{z}=32)$, respectively. However, as explained above, these $\mathrm{m} / \mathrm{z}$ ratios also occur as background signals in the other mass spectra. Nonetheless, $\mathrm{NO}_{2}{ }^{-}$ions $(46 \mathrm{u})$ can be associated with peak 2 , as a mass signal at $m / z=46$ occurs in addition to the background signals at $\mathrm{m} / \mathrm{z}=32$ and $\mathrm{m} / \mathrm{z}=48$. Furthermore, $\mathrm{CO}_{3}{ }^{-}$ions $(\mathrm{m} / \mathrm{z}=60)$ are found under peak 4 . However, the identification of the ion species underlying peak 1 is more difficult as the mass spectrum of peak 1 is almost identical to the mass spectrum of the baseline in section a and exhibits only the background signals at $\mathrm{m} / \mathrm{z}=32$ and $\mathrm{m} / \mathrm{z}=48$. Nonetheless, taken into account the predictions of the kinetic model, we speculate that this signal is composed of $\mathrm{O}^{-}$ions $(\mathrm{m} / \mathrm{z}=16)$ although corresponding signals are not observed in the mass spectrum. Here, it is important to note that masses below $\mathrm{m} / \mathrm{z}=20$ are significantly discriminated in the transfer stage of the HiKE-IMS-MS ${ }^{9}$ and may be suppressed. 
Comparing the reduced ion mobilities determined in this work with reduced ion mobilities from the literature for a temperature of $300 \mathrm{~K}$ and a reduced drift field strength of $80 \mathrm{Td}$ as listed in Table 3, the allocation of peak 1 to $\mathrm{O}^{-}$ions seems to be reasonable. However, as the mobilities from literature in Table 3 are determined at different background water concentrations and operating pressures, the mobility-based identification of peak 1 is only valid to a limited extend. Furthermore, as shown below, measurements at elevated $\mathrm{H}_{2} \mathrm{O}$ concentrations indicate that $\mathrm{OH}^{-}$ions are also covered by peak 1 . Thus, it is not clear whether peak 1 is composed of $\mathrm{O}^{-}, \mathrm{OH}^{-}$, or both.

Table 3: Reduced ion mobilities measured in this work in comparison to reduced ion mobilities from the literature (all given values refer to a reduced electric drift field strength of $80 \mathrm{Td}$ and a temperature of $300 \mathrm{~K}$ ).

\begin{tabular}{|l|l|l|l|l|}
\hline & \multicolumn{2}{|l|}{$\begin{array}{l}\text { Reduced ion mobility } \\
\text { in air in } \mathbf{c m}^{2} / \mathrm{Vs}\end{array}$} & $\begin{array}{l}\text { Reduced ion mobility } \\
\text { in } \mathrm{O}_{2} \text { in } \mathbf{c m}^{2} / \mathbf{V s}\end{array}$ & $\begin{array}{l}\text { Reduced ion mobility } \\
\text { in He in } \mathrm{cm}^{2} / \mathrm{Vs}\end{array}$ \\
\hline & $\begin{array}{l}\text { This } \\
\text { work }\end{array}$ & $\begin{array}{l}\text { Reference } \\
60,61\end{array}$ & Reference & \\
\hline $\mathbf{O}^{-}$ & 4.45 & 4.49 & 4.43 & Reference \\
\hline $\mathrm{OH}^{-}$ & & & & 17.62 \\
\hline $\mathrm{NO}_{2}^{-}$ & 3.07 & 3.05 & & 16.4 \\
\hline $\mathrm{O}_{3}^{-}$ & 2.94 & 2.98 & 3.22 & 12.9 \\
\hline $\mathrm{CO}_{3}^{-}$ & 2.74 & & & \\
\hline $\mathbf{O}_{2}^{-}$ & 2.66 & 2.81 & 2.11 & 11.7 \\
\hline
\end{tabular}

Considering these results, two further effects are noteworthy. First, the reduced ion mobility of $\mathrm{O}_{2}{ }^{-}$is lower than the reduced ion mobility of $\mathrm{O}_{3}{ }^{-}$even though the molecular mass and shape of $\mathrm{O}_{2}$ in comparison to mass and shape of $\mathrm{O}_{3}$ suggest the opposite. This may be due to the effect of resonant charge transfer, which occurs when ions move in a gas containing the neutral precursors or molecules of similar structure. In this case, the transfer of an electron from an ion to a neutral occurs easily resulting in an increase of the effective ion neutral collision cross section and thus in a decrease of the mobility ${ }^{63-65}$. In the positive ion polarity mode, this effects leads to a significant decrease of the reduced ion mobility of $\mathrm{O}_{2}{ }^{+}$in air (containing 20 vol.- $\% \mathrm{O}_{2}$ ) in comparison to the reduced ion mobility of $\mathrm{O}_{2}{ }^{+}$in nitrogen ${ }^{9}$.

The distortion between the $\mathrm{O}_{3}{ }^{-}$signal and the $\mathrm{CO}_{3}{ }^{-}$signal is also a noteworthy finding. With regard to reaction $\left(22^{\prime}\right)$, this distortion strongly suggests the conversion of $\mathrm{O}_{3}{ }^{-}$ions to $\mathrm{CO}_{3}{ }^{-}$ions inside the drift region due to the residual $\mathrm{CO}_{2}$ concentration of $30 \mathrm{ppm}_{\mathrm{v}}$.

$$
\mathrm{O}_{3}{ }^{-}+\mathrm{CO}_{2} \rightarrow \mathrm{CO}_{3}{ }^{-}+\mathrm{O}_{2}
$$

In the following, the effect of the reduced electric reaction field strength on the negative reactant ion population is investigated in detail.

\section{Effect of the reduced electric reaction field strength on the negative reactant ion population}

Varying the reduced electric field strength in the reaction region, the kinetic energy of both, electrons and ions is changing. Furthermore, the ions' residence times in the reaction region und thus the total reaction times changes. These effects significantly influence the negative reactant ion population formed in the HiKE-IMS, as illustrated in Figure 5.

Figure $5 \mathrm{a}$ exhibits the recorded reactant ion spectra for different reduced electric field strengths in the reaction region containing purified air with $70 \mathrm{ppm}_{\mathrm{v}}$ of $\mathrm{H}_{2} \mathrm{O}$ and $30 \mathrm{ppm}_{\mathrm{v}}$ of $\mathrm{CO}_{2}$, while the reduced electric drift field strength was kept constant at $80 \mathrm{Td}$. Thus, the drift times of the ion species remain constant, when sweeping the reduced electric field strength in the reaction region. However, both, the amount of charge carriers as well as the ion population being injected into the drift region change. 
In Figure 5b, the charge underlying the peaks of the individual ion species as well as the charge underlying the total spectrum is plotted against the reduced electric reaction field strength. Here, the charge represents the area under the peaks. Taken into account the conversion reactions that likely proceed inside the drift region, the integral limits are chosen as indicated in Figure 5a. Increasing the reduced electric reaction field strength, the total charge in the spectrum increases. This is mainly due to an effect explained and theoretically described by Kirk et al. ${ }^{66}$ : While traveling through the reaction region, the charge carrier beam generated in the corona discharge source expands radially due to coulomb repulsion, causing charge carriers to be lost at the ring electrodes. As the charge carrier beam has less time to expand and the charge density is lower at higher velocities, the ion current reaching the the end of the reaction region grows with the reduced electric reaction field strength. According to Kirk et al. ${ }^{66}$, this effect results in a quadratic increase of the total charge in the spectrum. However, the curve depicted in Figure $5 b$ shows small deviations from a quadratic growth. These deviations might be due to the field-dependent electron attachment efficiency. Figure $5 c$ illustrates the theoretically predicted electron attachment coefficient as a function of the reduced electric reaction field strength. According to the kinetic model, at a reduced electric reaction field strength of $20 \mathrm{Td}$, $6 \%$ of the electrons released during the corona discharge attach to neutrals inside the reaction region, while at a reduced electric reaction field strength of $100 \mathrm{Td}, 19 \%$ of the electrons attach to neutrals. At reduced electric reaction field strengths around $50 \mathrm{Td}$, this value reaches a minimum.

In addition to the total charge underlying the spectrum, the composition of the negative reactant ion population changes with the reduced electric reaction field strength. In Figure $5 d$, the measured relative abundances of every individual ion species are plotted against the reduced electric reaction field strength. The relative abundance of an individual ion species is calculated from the charge underlying the peak of the respective ion species divided by the total charge underlying the spectrum. As shown in Figure $5 \mathrm{~d}$, increasing the reduced electric field strength, the relative abundance of $\mathrm{CO}_{3}{ }^{-}$in the spectrum continously decreases. Simultaneously, the relative abundance of $\mathrm{O}_{3}{ }^{-}$increases and reaches a maximum at a reduced electric reaction field strength around $50 \mathrm{Td}$. At reduced electric reaction field strength exceeding $50 \mathrm{Td}$, the relative abundances of $\mathrm{O}_{3}{ }^{-}$decreases while those of $\mathrm{O}_{2}{ }^{-}$as well as $\mathrm{O}^{-}$and $\mathrm{OH}^{-}$increase. The simulated relative abundances are in good qualitative agreement with the experimental results, see Figure $5 \mathrm{e}$. According to the kinetic model, the continous decrease of the relative abundance of $\mathrm{CO}_{3}{ }^{-}$is mainly due to a reduction of the available reaction time between $\mathrm{CO}_{2}$ and $\mathrm{O}_{3}{ }^{-}$as well as $\mathrm{O}^{-}$according to reactions $\left(19^{\prime}\right)$ and $\left(22^{\prime}\right)$.

$$
\begin{gathered}
\mathrm{O}^{-}+\mathrm{CO}_{2}+\mathrm{M} \rightleftharpoons \mathrm{CO}_{3}{ }^{-}+\mathrm{M} \\
\mathrm{O}_{3}{ }^{-}+\mathrm{CO}_{2} \rightarrow \mathrm{CO}_{3}{ }^{-}+\mathrm{O}_{2}
\end{gathered}
$$

The increase of the relative abundance of $\mathrm{O}_{3}{ }^{-}$between $20 \mathrm{Td}$ and $50 \mathrm{Td}$ can be explained by the fielddependence of reactions $\left(1^{\prime}\right)$ and $\left(2^{\prime}\right)$.

$$
\begin{gathered}
e^{-}+O_{2}+M \rightarrow O_{2}^{-}+M \\
e^{-}+O_{2} \rightarrow O^{-}+O
\end{gathered}
$$

Within this Td range, the direct electron attachment process $\left(1^{\prime}\right)$ resulting in $\mathrm{O}_{2}^{-}$ions is increasingly shifted towards the dissociative electron attachment process $\left(2^{\prime}\right)$ resulting in $\mathrm{O}^{-}$ions, which react via reaction $\left(5^{\prime}\right)$ to $\mathrm{O}_{3}$. Increasing the reduced electric reaction field strength further, the relative abundance of $\mathrm{O}_{3}{ }^{-}$decreases and that of $\mathrm{O}_{2}{ }^{-}$increases as reaction $\left(6^{\prime}\right)$ is favored over reaction $\left(5^{\prime}\right)$ in this range.

$$
\begin{gathered}
\mathrm{O}^{-}+\mathrm{O}_{2}+M \rightarrow \mathrm{O}_{3}{ }^{-}+M \\
\mathrm{O}^{-}+\mathrm{O}_{2} \rightarrow \mathrm{O}_{2}{ }^{-}+O
\end{gathered}
$$


It is noteworthy that the kinetic model predicts a significant higher $\mathrm{O}^{-}$abundance at high reduced electric field strengths than the measurements show. This discrepancy might be due to the rapid conversion of $\mathrm{O}^{-}$to $\mathrm{O}_{3}{ }^{-}, \mathrm{CO}_{3}{ }^{-}$or $\mathrm{O}_{2}{ }^{-}$inside the drift region. Thus, it is most likely that the peaks of $\mathrm{O}_{3}{ }^{-}$, $\mathrm{CO}_{3}{ }^{-}$and $\mathrm{O}_{2}^{-}$also contain charge that can be assigned to $\mathrm{O}^{-}$. However, these fractions are not easily distinguished in the HiKE-IMS spectrum. Nonetheless, the kinetic model reaches a good qualitative agreement with the measurements although it provides the negative ion population at the end of the reaction region while the measurements show the negative ion population at the Faraday detector at the end of the drift region.

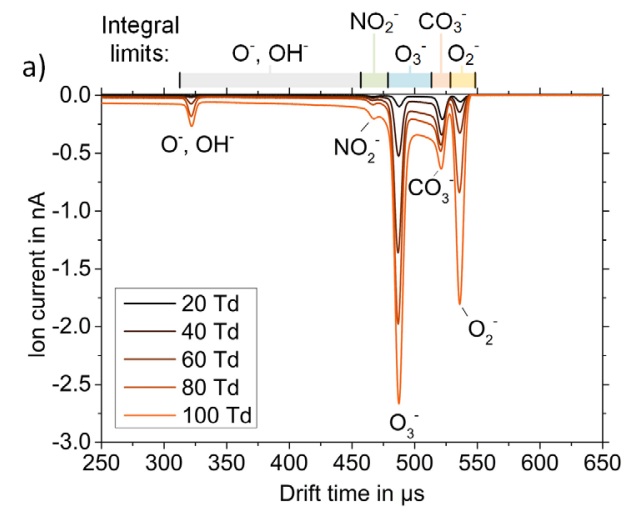

b)
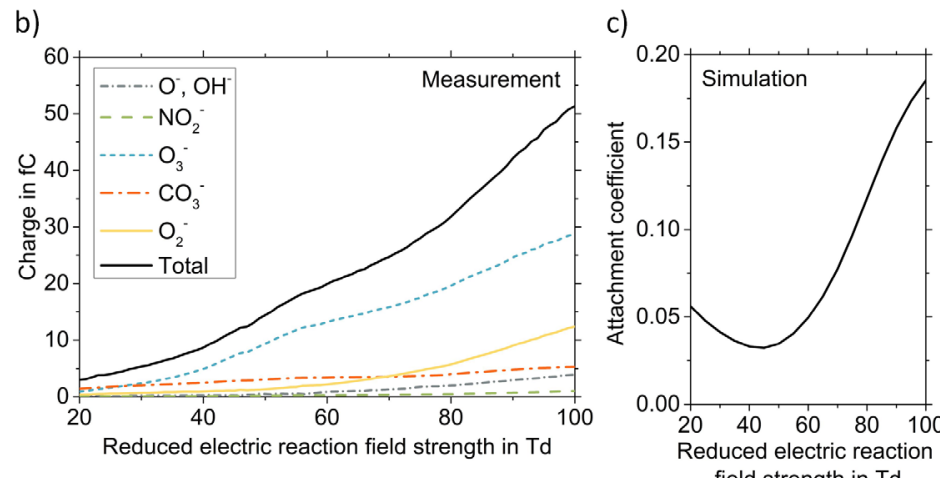

d)
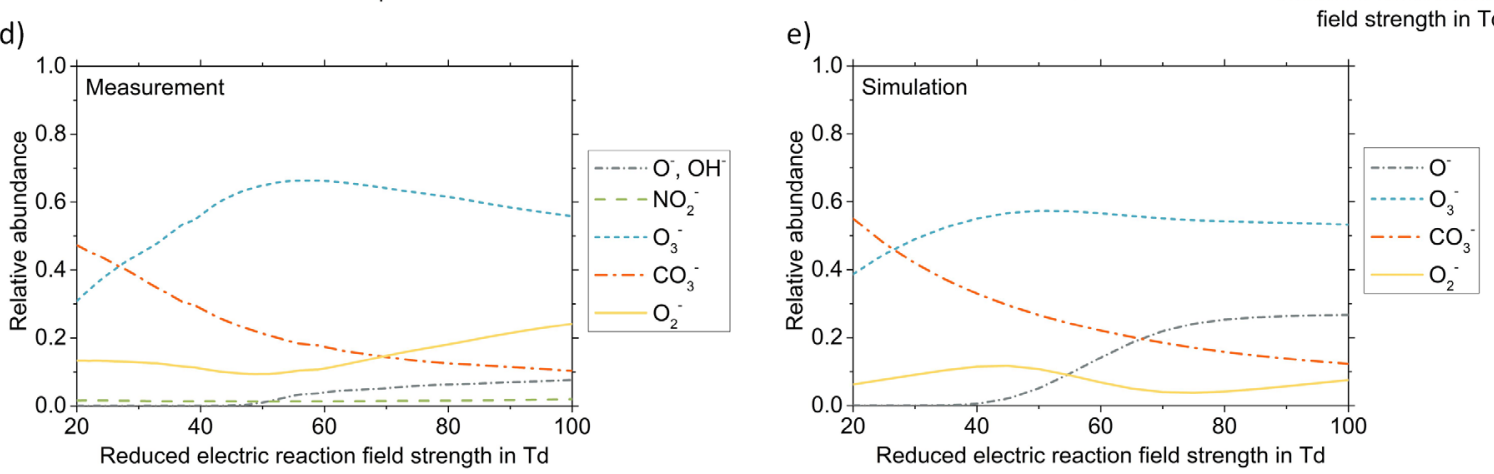

Figure 5: Variation of the reduced electric reaction field strength at a constant reduced electric drift field strength of $80 \mathrm{Td}$, the $\mathrm{H}_{2} \mathrm{O}$ and $\mathrm{CO}_{2}$ concentrations in reaction and drift region are $70 \mathrm{ppm}_{v}$ and $30 \mathrm{ppm}_{v}$, respectively. The pressure is $14.3 \mathrm{mbar}$, the temperature is $45^{\circ} \mathrm{C}$. a) Recorded ion mobility spectra at different reduced electric reaction field strengths, $b$ ) measured charge underlying the peaks in the spectrum as a function of the reduced electric reaction field strength, c) simulated fraction of electrons that have attached to neutrals inside the reaction region as a function of the reduced electric reaction field strength, d) measured relative abundances of the ion species forming the ion mobility spectra as a function of the reduced electric reaction field strength, e) simulated relative abundances of the ion species as a function of the reduced electric reaction field strength.

In summary, the negative reactant ion population in $\mathrm{HiKE}-\mathrm{IMS}$ at $70 \mathrm{ppm}_{\mathrm{v}} \mathrm{H}_{2} \mathrm{O}$ and $30 \mathrm{ppm}_{\mathrm{v}} \mathrm{CO}_{2}$ in the reaction region is dominated by the oxygen-based ions $\mathrm{O}^{-}, \mathrm{O}_{2}^{-}$and $\mathrm{O}_{3}^{-}$. Only small amounts of $\mathrm{NO}_{2}^{-}$and $\mathrm{CO}_{3}{ }^{-}$ions are observed. However, when using the HiKE-IMS in field applications with a direct sample gas inlet, the concentrations of $\mathrm{H}_{2} \mathrm{O}$ and $\mathrm{CO}_{2}$ in the reaction region are significantly higher than $70 \mathrm{ppm}_{\mathrm{v}}$ and $30 \mathrm{ppm}_{\mathrm{v}}$, respectively. Therefore, the negative reactant ion population is investigated in dependence on the $\mathrm{H}_{2} \mathrm{O}$ and $\mathrm{CO}_{2}$ concentration in the following.

\section{Effect of $\mathrm{H}_{2} \mathrm{O}$ and $\mathrm{CO}_{2}$ on the negative reactant ion population}

Figure 6a shows the recorded HiKE-IMS spectra at a reduced electric reaction field strength of $80 \mathrm{Td}$ and a $\mathrm{CO}_{2}$ concentration of $30 \mathrm{ppm}_{\mathrm{v}}$ for various $\mathrm{H}_{2} \mathrm{O}$ concentrations in the reaction region. Furthermore, Figure $6 \mathrm{~b}$ depicts the charge underlying the peaks of the individual ion species as well as the charge underlying the total spectrum as a function of the $\mathrm{H}_{2} \mathrm{O}$ concentration in the reaction region given as relative humidity $(\mathrm{rH})$ referring to $298 \mathrm{~K}$ and $1013 \mathrm{mbar}$. The relative humidity in the reaction 
region is varied by altering relative sample gas humidity. This leads to a relative humidity in the reaction region of about half the relative sample gas humidity due to mixing the sample gas with comparably dry drift gas in the reaction region. Increasing the relative humidity in the reaction region, the charge underlying peak $1\left(\mathrm{~K}_{0}=4.45 \mathrm{~cm}^{2} / \mathrm{Vs}\right)$, presumable consisting of $\mathrm{O}^{-}$or $\mathrm{OH}^{-}$ions increases, whereas the charge underlying the peaks of the other ions $\left(\mathrm{NO}_{2}{ }^{-}, \mathrm{O}_{3}{ }^{-}, \mathrm{CO}_{3}{ }^{-}\right.$and $\left.\mathrm{O}_{2}{ }^{-}\right)$remains almost constant. Thus, the total charge underlying the spectrum increases with increasing relative humidity in the reaction region. This effect can be explained by an increased electron attachment efficiency at elevated humidities. As illustrated by the simulated electron attachment coefficient in Figure $6 c$, at a relative humidity of $0.4 \%$ (70 ppm $\mathrm{v}$ of water) in the reaction region, the kinetic model predicts that about $12 \%$ of the electrons injected into reaction region attach to neutrals while traversing the reaction region. In contrast, at a relative humidity of $19 \%$ (3800 ppm $\mathrm{v}_{\mathrm{v}}$ of water), about $21 \%$ of the electrons attach to neutrals while traversing the reaction region. The increase of the electron attachment coefficient is due to the additional dissociative attachment processes $\left(7^{\prime}\right),\left(8^{\prime}\right)$, and $\left(9^{\prime}\right)$ which occur in the presence of $\mathrm{H}_{2} \mathrm{O}$.

$$
\begin{aligned}
e^{-}+\mathrm{H}_{2} \mathrm{O} & \rightarrow \mathrm{O}^{-}+\mathrm{H}_{2} \\
e^{-}+\mathrm{H}_{2} \mathrm{O} & \rightarrow \mathrm{H}^{-}+\mathrm{OH} \\
e^{-}+\mathrm{H}_{2} \mathrm{O} & \rightarrow \mathrm{OH}^{-}+\mathrm{H}
\end{aligned}
$$

However, $\mathrm{H}^{-}$ions are not stable. As stated above, $\mathrm{H}^{-}$ions may either lose their charge in the detachment reaction $\left(10^{\prime}\right)$ or they may react to $\mathrm{OH}^{-}$ions when colliding with water according to reaction $\left(13^{\prime}\right)$.

$$
\begin{gathered}
\mathrm{H}^{-}+\mathrm{O}_{2} \rightarrow \mathrm{HO}_{2}+e^{-} \\
\mathrm{H}^{-}+\mathrm{H}_{2} \mathrm{O} \rightarrow \mathrm{OH}^{-}+\mathrm{H}_{2}
\end{gathered}
$$

In the presence of $\mathrm{H}_{2} \mathrm{O}, \mathrm{O}^{-}$ions may also initiate the formation of $\mathrm{OH}^{-}$ions via reactions $\left(12^{\prime}\right)$ as well as reaction (14') followed by reaction (15').

$$
\begin{aligned}
\mathrm{O}^{-}+\mathrm{H}_{2} \mathrm{O} & \rightarrow \mathrm{OH}^{-}+\mathrm{OH} \\
\mathrm{O}^{-}+\mathrm{H}_{2} \mathrm{O}+\mathrm{M} & \rightleftharpoons \mathrm{O}^{-}\left(\mathrm{H}_{2} \mathrm{O}\right)+\mathrm{M} \\
\mathrm{O}^{-}\left(\mathrm{H}_{2} \mathrm{O}\right)+\mathrm{H}_{2} \mathrm{O} & \rightarrow \mathrm{OH}^{-}\left(\mathrm{H}_{2} \mathrm{O}\right)+\mathrm{OH}
\end{aligned}
$$

Thus, the presence of $\mathrm{H}_{2} \mathrm{O}$ mainly results in the formation of additional $\mathrm{OH}^{-}$ions. The formation of $\mathrm{OH}^{-}$ ions is experimentally confirmed by the detection of $\mathrm{HCO}_{3}{ }^{-}$ions at high relative humidities, see Figure 6 d. According to reaction $\left(21^{\prime}\right), \mathrm{HCO}_{3}{ }^{-}$ions result from a reaction between $\mathrm{OH}^{-}$and $\mathrm{CO}_{2}$.

$$
\mathrm{OH}^{-}+\mathrm{CO}_{2}+\mathrm{M} \rightleftharpoons \mathrm{HCO}_{3}{ }^{-}+\mathrm{M}
$$

The results predicted by the kinetic model also confirm these findings. As illustrated by the theoretical results shown in Figure $6 \mathrm{e}$, increasing the relative humidity, the relative abundances of $\mathrm{OH}^{-}$and $\mathrm{HCO}_{3}{ }^{-}$ increase. 
a)

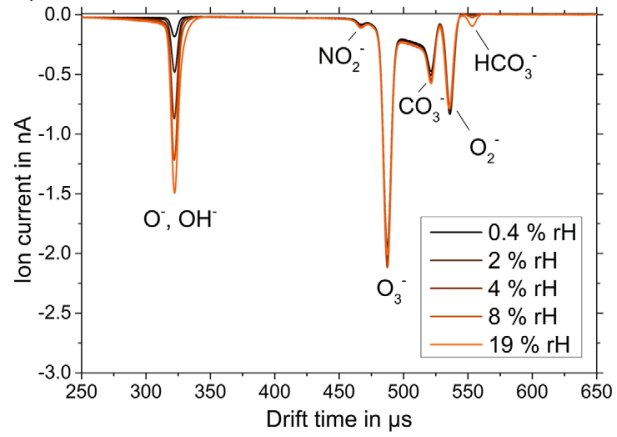

d)

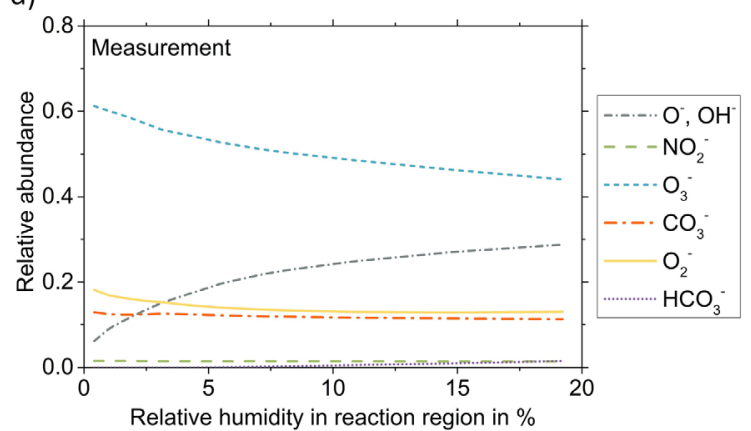

b)

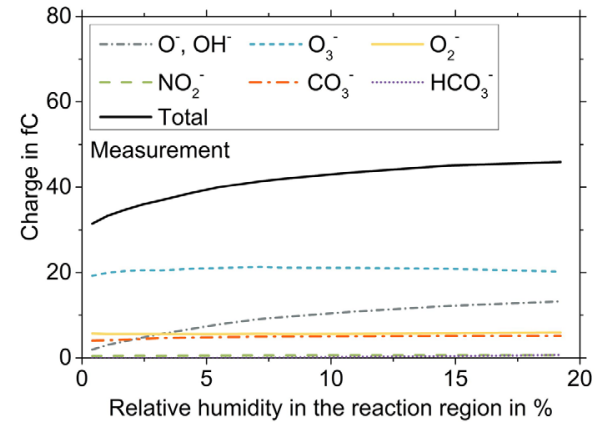

e) c)

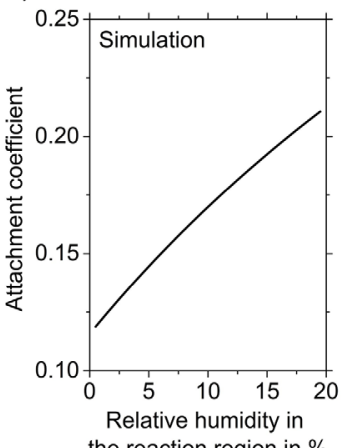

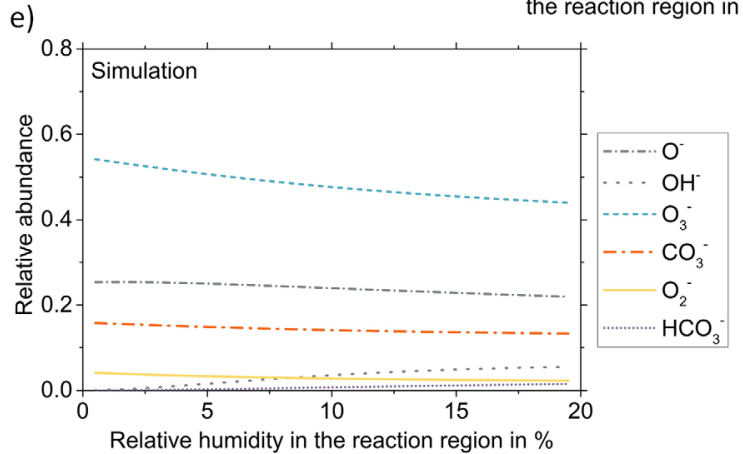

Figure 6: Variation of the relative humidity in the reaction region at constant reduced electric reaction field strength of $80 \mathrm{Td}$ and constant reduced electric drift field strength of $80 \mathrm{Td}$, the $\mathrm{CO}_{2}$ concentration in the reaction region is $30 \mathrm{ppm}_{\mathrm{v}}$, the $\mathrm{H}_{2} \mathrm{O}$ and $\mathrm{CO}_{2}$ concentrations in the drift region are $70 \mathrm{ppm}_{v}$ and $30 \mathrm{ppm}_{v}$, respectively. The pressure is $14.3 \mathrm{mbar}$, the temperature is $45^{\circ} \mathrm{C}$. a) Recorded ion mobility spectra at different relative humidities in the reaction region, b) measured charge underlying the peaks in the spectrum as a function of the relative humidity in the reaction region, c) simulated fraction of electrons that have attached to neutrals inside the reaction region as a function of the relative humidity in the reaction region, $d$ ) measured relative abundances of the ion species forming the ion mobility spectra as a function of the relative humidity in the reaction region, e) simulated relative abundances of the ion species as a function of the relative humidity in the reaction region.

Figure 7a shows the recorded HiKE-IMS spectra at a reduced electric reaction field strength of $80 \mathrm{Td}$ and a $\mathrm{H}_{2} \mathrm{O}$ concentration of $70 \mathrm{ppm}_{\mathrm{v}}$ for various $\mathrm{CO}_{2}$ concentrations in the reaction region. Furthermore, Figure $7 \mathrm{~b}$ depicts the charge underlying the peaks of the individual ion species as well as the charge underlying the total spectrum as a function of the $\mathrm{CO}_{2}$ concentration in the reaction region. The $\mathrm{CO}_{2}$ concentration in the reaction region is varied by altering the $\mathrm{CO}_{2}$ concentration in the sample gas. Again, taking into account the mixing of the sample gas with drift gas containing $30 \mathrm{ppm}_{\mathrm{v}}$ of $\mathrm{CO}_{2}$ in the reaction region, $\mathrm{CO}_{2}$ concentrations between $30 \mathrm{ppm}_{\mathrm{v}}$ and $950 \mathrm{ppm}_{\mathrm{v}}$ in the sample gas correspond to $\mathrm{CO}_{2}$ concentration between $30 \mathrm{ppm}_{\mathrm{v}}$ and $490 \mathrm{ppm}_{\mathrm{v}}$ in the reaction region. Increasing the $\mathrm{CO}_{2}$ concentration in the reaction region, the total charge in the spectrum remains almost constant, see Figure $7 b$. This is in accordance with the simulated electron attachment coefficient in Figure 7c, which increases only slightly with increasing $\mathrm{CO}_{2}$ concentration. Instead, the recorded HiKE-IMS spectra are determined by conversion processes, as shown in Figure 7d. According to reaction (22'), $\mathrm{O}_{3}{ }^{-}$is converted to $\mathrm{CO}_{3}{ }^{-}$when colliding with $\mathrm{CO}_{2}$.

$$
\mathrm{O}_{3}{ }^{-}+\mathrm{CO}_{2} \rightarrow \mathrm{CO}_{3}{ }^{-}+\mathrm{O}_{2}
$$

Thus, both the experimental results in Figure $7 \mathrm{~d}$ as well as the theoretical results in Figure 7 e show that the relative abundance of $\mathrm{O}_{3}{ }^{-}$decreases while the relative abundance of $\mathrm{CO}_{3}{ }^{-}$increases with increasing $\mathrm{CO}_{2}$ concentration. It is noted that the relative abundance of $\mathrm{O}_{2}{ }^{-}$in the experimental and theoretical results remains almost constant, although reaction $\left(20^{\prime}\right)$ suggests the conversion of $\mathrm{O}_{2}^{-}$to $\mathrm{CO}_{4}{ }^{-}$with increasing $\mathrm{CO}_{2}$ concentration.

$$
\mathrm{O}_{2}^{-}+\mathrm{CO}_{2}+\mathrm{M} \rightleftharpoons \mathrm{CO}_{4}^{-}+\mathrm{M}
$$


However, as stated above, the dissociation enthalpy of $\mathrm{CO}_{4}{ }^{-}$is comparably low $(19 \mathrm{kcal} / \mathrm{mol})$. According to the kinetic model, $\mathrm{CO}_{4}^{-}$thus dissociates in $\mathrm{O}_{2}^{-}$and $\mathrm{CO}_{2}$ at reduced electric reaction field strength exceeding $65 \mathrm{Td}$. As the measurements presented in Figure 7 are performed at a reduced electric reaction field strength of $80 \mathrm{Td}, \mathrm{CO}_{4}{ }^{-}$ions are not observed in the spectra and the relative abundance of $\mathrm{O}_{2}^{-}$remains constant.

a)

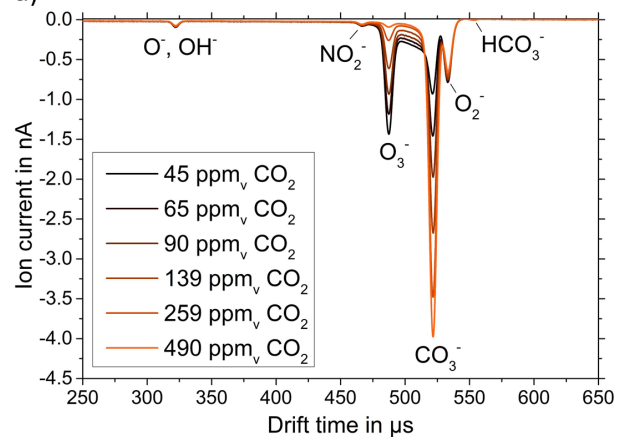

d)

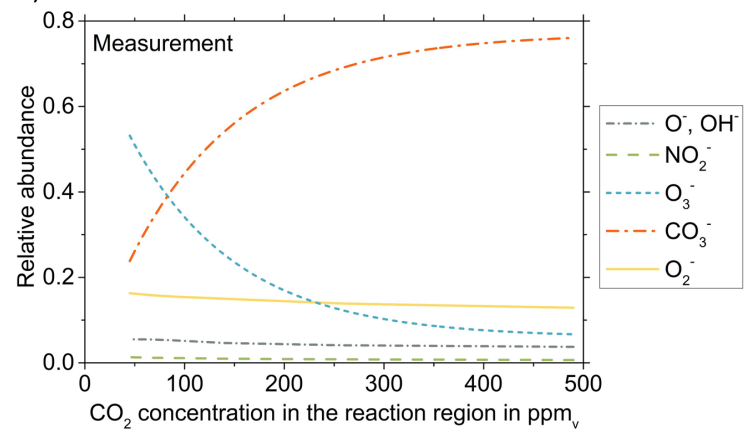

b)

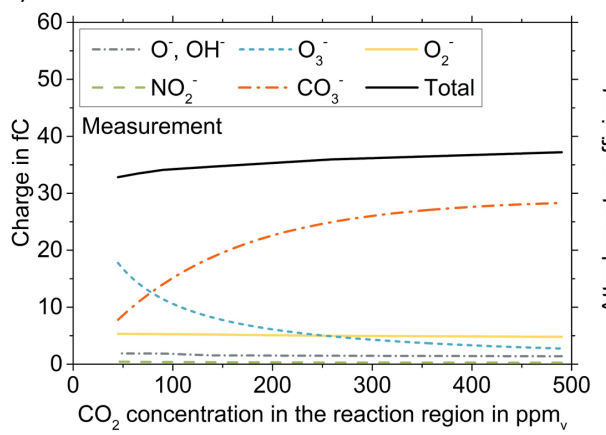

e) c)

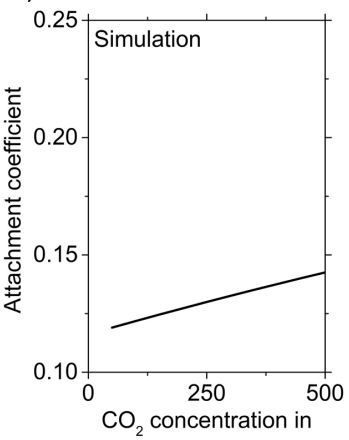

the reaction region in $\mathrm{ppm}_{v}$

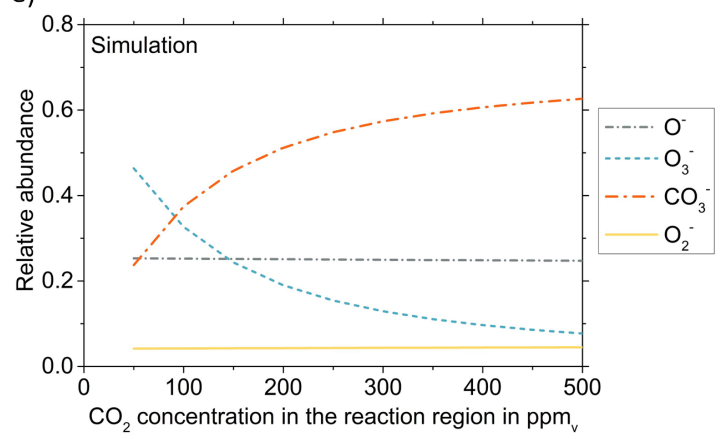

Figure 7: Variation of the $\mathrm{CO}_{2}$ concentration in the reaction region at constant reduced electric reaction field strength of $80 \mathrm{Td}$ and constant reduced electric drift field strength of $80 \mathrm{Td}$, the $\mathrm{H}_{2} \mathrm{O}$ concentration in the reaction region is $70 \mathrm{ppm}_{\mathrm{v}}$, the $\mathrm{H}_{2} \mathrm{O}$ and $\mathrm{CO}_{2}$ concentrations in the drift region are $70 \mathrm{ppm}_{v}$ and $30 \mathrm{ppm}_{v}$, respectively. The pressure is $14.3 \mathrm{mbar}$, the temperature is $45^{\circ} \mathrm{C}$. a) Recorded ion mobility spectra at different $\mathrm{CO}_{2}$ concentrations in the reaction region, $b$ ) measured charge underlying the peaks in the spectrum as a function of the $\mathrm{CO}_{2}$ concentration in the reaction region, c) simulated fraction of electrons that have attached to neutrals inside the reaction region as a function of the $\mathrm{CO}_{2}$ concentration in the reaction region, d) measured relative abundances of the ion species forming the ion mobility spectra as a function of the $\mathrm{CO}_{2}$ concentration in the reaction region, e) simulated relative abundances of the ion species as a function of the $\mathrm{CO}_{2}$ concentration in the reaction region.

\section{Comparison of the ion chemistry in HiKE-IMS and classical IMS}

In contrast to classical IMS operating at ambient pressure, the HiKE-IMS presented in this work is operated at a pressure of 14.3 mbar. Furthermore, classical ambient pressure IMS are typically operated at reduced electric field strengths of a few $\mathrm{Td}$ whereas the HiKE-IMS uses reduced electric field strengths of up to $100 \mathrm{Td}$. These two aspects lead to significant differences between the negative ion chemistry in HiKE-IMS and that in classical ambient pressure IMS.

While the reaction systems reach very quickly chemical equilibrium at ambient pressure, the results presented above show that the reaction systems in HiKE-IMS at 14.3 mbar are far from being in equilibrium. As ions reach the end of the reaction region in HiKE-IMS before the chemical equilibrium is established, the negative HiKE-IMS spectra are influenced by reactions inside the drift region leading to e.g. a raised baseline and distorted peaks. This is mainly due to the presence of electrons and reactive $\mathrm{O}^{-}$ions.

Additionally, the reaction cascades in HiKE-IMS significantly differ from those in classical IMS. According to the field-dependence of reactions $\left(1^{\prime}\right)$ and $\left(2^{\prime}\right)$, the primary ion $\mathrm{O}^{-}$predominates in HiKE- 
IMS whereas the primary ion $\mathrm{O}_{2}^{-}$is dominant in classical IMS operating at low reduced electric field strengths and comparably high background pressures.

$$
\begin{gathered}
e^{-}+O_{2}+M \rightarrow O_{2}^{-}+M \\
e^{-}+O_{2} \rightarrow O^{-}+O
\end{gathered}
$$

Thus, depending on the background concentrations of $\mathrm{H}_{2} \mathrm{O}$ and $\mathrm{CO}_{2}$, mainly $\mathrm{O}_{2}^{-}\left(\mathrm{H}_{2} \mathrm{O}\right)_{n}$ and $\mathrm{CO}_{4}{ }^{-}\left(\mathrm{H}_{2} \mathrm{O}\right)_{n}$ as well as $\mathrm{OH}^{-}\left(\mathrm{H}_{2} \mathrm{O}\right)_{n}$ ions are detected in classical IMS ${ }^{28,67,68,14,15,18}$. In contrast, the negative reactant ion population in HiKE-IMS is predominated by $\mathrm{O}_{3}{ }^{-}, \mathrm{O}^{-}$and $\mathrm{CO}_{3}{ }^{-}$ions. However, to estimate the effect of these differences on the ionization processes occurring in HiKE-IMS, further in-depth studies are required.

\section{Conclusion}

In this work, the observed negative reactant ion population in HiKE-IMS is investigated in detail. We investigated the mechanisms leading to the formation of negative reactant ions in HiKE-IMS. Based on kinetic and thermodynamic data from literature, we developed a model describing the underlying processes. This model is in a good qualitative agreement with the measurements. For identification of the corresponding ion species of a certain mobility range or a distinct peak of the ion mobility spectrum, a self-built HiKE-IMS-MS with a second ion gate controlling the ion transfer into the MS was used. It is shown, that the negative reactant ion population is highly sensitive to concentrations of abundant atmospheric background constituents, predominantly $\mathrm{CO}_{2}$ and $\mathrm{H}_{2} \mathrm{O}$. In dry purified air containing $70 \mathrm{ppm}_{\mathrm{v}}$ of $\mathrm{H}_{2} \mathrm{O}$ and $30 \mathrm{ppm}_{\mathrm{v}}$ of $\mathrm{CO}_{2}$, the HiKE-IMS spectrum is dominated by $\mathrm{O}^{-}, \mathrm{O}_{2}{ }^{-}$and $\mathrm{O}_{3}{ }^{-}$ . Additionally, small amounts of $\mathrm{NO}_{2}^{-}$and $\mathrm{CO}_{3}{ }^{-}$are observed. At elevated $\mathrm{H}_{2} \mathrm{O}$ concentrations, the abundance of $\mathrm{OH}^{-}$is increased, whereas at elevated $\mathrm{CO}_{2}$ concentrations, $\mathrm{CO}_{3}{ }^{-}$ions are the most abundant ion species. Furthermore, the negative reactant ion population is influenced by the reduced electric field strength in the reaction region, as this parameter affects the kinetic energy of electrons and ions as well as the total reaction time in the reaction region. Due to the variety of different reactant ion species, the ionization of analyte molecules in the negative ion polarity mode may become rather complex. Various ionization pathways are possible originating from individual reactant ion species and resulting in the formation of one or several product ion species in HiKE-IMS. Thus, further in-depth studies are required regarding the occurring ionization mechanisms of specific analyte molecules.

\section{Acknowledgment}

This work was funded by the Deutsche Forschungsgemeinschaft (DFG, German Research Foundation, joint project BE 2124/8-1 - ZI 1288/8-1)

\section{References}

(1) Langejuergen, J.; Allers, M.; Oermann, J.; Kirk, A. T.; Zimmermann, S. High kinetic energy ion mobility spectrometer: quantitative analysis of gas mixtures with ion mobility spectrometry. Analytical chemistry 2014, 86, 7023-7032.

(2) Langejuergen, J.; Allers, M.; Oermann, J.; Kirk, A. T.; Zimmermann, S. Quantitative detection of benzene in toluene- and xylene-rich atmospheres using high-kinetic-energy ion mobility spectrometry (IMS). Analytical chemistry 2014, 86, 11841-11846.

(3) Kirk, A. T.; Grube, D.; Kobelt, T.; Wendt, C.; Zimmermann, S. High-Resolution High Kinetic Energy Ion Mobility Spectrometer Based on a Low-Discrimination Tristate Ion Shutter. Analytical chemistry 2018, 90, 5603-5611.

(4) Ellis, A. M.; Mayhew, C. A. Proton Transfer Reaction Mass Spectrometry; John Wiley \& Sons, Ltd: Chichester, UK, 2014.

(5) Shvartsburg, A. A. Differential ion mobility spectrometry; CRC Press: Boca Raton, 2009. 
(6) Kolakowski, B. M.; Mester, Z. Review of applications of high-field asymmetric waveform ion mobility spectrometry (FAIMS) and differential mobility spectrometry (DMS). The Analyst 2007, 132, 842-864.

(7) Chiluwal, U.; Lee, G.; Rajapakse, M. Y.; Willy, T.; Lukow, S.; Schmidt, H.; Eiceman, G. A. Tandem ion mobility spectrometry at ambient pressure and field decomposition of mobility selected ions of explosives and interferences. The Analyst 2019, 144, 2052-2061.

(8) Bohnhorst, A.; Kirk, A. T.; Yin, Y.; Zimmermann, S. Ion Fragmentation and Filtering by Alpha Function in Ion Mobility Spectrometry for Improved Compound Differentiation. Analytical chemistry 2019, 91, 8941-8947.

(9) Allers, M.; Kirk, A. T.; Roßbitzky, N. von; Erdogdu, D.; Hillen, R.; Wissdorf, W.; Benter, T.; Zimmermann, S. Analyzing Positive Reactant lons in High Kinetic Energy lon Mobility Spectrometry (HiKE-IMS) by HiKE-IMS-MS. Journal of the American Society for Mass Spectrometry 2020, 31, 812821.

(10) Allers, M.; Kirk, A. T.; Eckermann, M.; Schaefer, C.; Erdogdu, D.; Wissdorf, W.; Benter, T.; Zimmermann, S. Positive Reactant Ion Formation in High Kinetic Energy lon Mobility Spectrometry (HiKE-IMS). Journal of the American Society for Mass Spectrometry 2020, 31, 1291-1301.

(11) Shahin, M. M. Ionic Reactions in Corona Discharges of Atmospheric Gases. In: Blaustein (Hg.) 1969 - Chemical Reactions in Electrical Discharges 1969, 80, 48-58.

(12) Gardiner, P. S.; Craggs, J. D. Negative ions in Trichel corona in air. Journal of Physics D: Applied Physics 1977, 10, 1003-1009.

(13) Gravendeel, B.; Hoog, F. J. d. Clustered negative ions in atmospheric negative corona discharges in the Trichel regime. Journal of Physics D: Applied Physics 1987, 20, 6337-6361.

(14) Ross, S. K.; Bell, A. J. Reverse flow continuous corona discharge ionisation applied to ion mobility spectrometry. International Journal of Mass Spectrometry 2002, 218, L1-L6.

(15) Hill, C. A.; Thomas, C. L. P. A pulsed corona discharge switchable high resolution ion mobility spectrometer-mass spectrometer. The Analyst 2003, 128, 55-60.

(16) Skalny, J. D.; Mikoviny, T.; Matejcik, S.; Mason, N. J. An analysis of mass spectrometric study of negative ions extracted from negative corona discharge in air. International Journal of Mass Spectrometry 2004, 233, 317-324.

(17) Sekimoto, K.; Takayama, M. Influence of needle voltage on the formation of negative core ions using atmospheric pressure corona discharge in air. International Journal of Mass Spectrometry 2007, 261, 38-44.

(18) Sabo, M.; Matúška, J.; Matejčík, S. Specific $\mathrm{O}_{2}^{-}$generation in corona discharge for ion mobility spectrometry. Talanta 2011, 85, 400-405.

(19) Cochems, P.; Kirk, A. T.; Zimmermann, S. In-circuit-measurement of parasitic elements in high gain high bandwidth low noise transimpedance amplifiers. Review of Scientific Instruments 2014, 85, 124703.

(20) Li, B.; Li, X.; Fu, M.; Zhuo, R.; Wang, D. Effect of humidity on dielectric breakdown properties of air considering ion kinetics. Journal of Physics D: Applied Physics 2018, 51, 375201.

(21) Zhao, H.; Lin, H. Dielectric breakdown properties of N2-O2 mixtures by considering electron detachments from negative ions. Physics of Plasmas 2016, 23, 73505.

(22) Pancheshnyi, S. Effective ionization rate in nitrogen-oxygen mixtures. Journal of Physics $D$ : Applied Physics 2013, 46, 155201.

(23) Ponomarev, A. A.; Aleksandrov, N. L. Kinetics of Energetic O- Ions in the Discharge Plasmas of Water Vapor and H2O-Containing Mixtures. Plasma Physics Reports 2018, 44, 986-995.

(24) Haefliger, P.; Hösl, A.; Franck, C. M. Experimentally derived rate coefficients for electron ionization, attachment and detachment as well as ion conversion in pure $\mathrm{O} 2$ and $\mathrm{N2}-\mathrm{O} 2$ mixtures. Journal of Physics D: Applied Physics 2018, 51, 355201. 
(25) Sun, Y.; Liu, X.; Dong, K.; Xie, C. Corona discharge effect on charge and energy transfer in dielectric barrier discharge. Physica Scripta 2019, 94, 85602.

(26) Linstrom, P. NIST Chemistry WebBook, NIST Standard Reference Database 69; National Institute of Standards and Technology, 1997.

(27) Chanin, L. M.; Phelps, A. V.; Biondi, M. A. Measurements of the Attachment of Low-Energy Electrons to Oxygen Molecules. Physical Review 1962, 128, 219-230.

(28) Spangler, G. E.; Collins, C. I. Reactant ions in negative ion plasma chromatography. Analytical chemistry 1975, 47, 393-402.

(29) Kučera, M.; Stano, M.; Wnorowska, J.; Barszczewska, W.; Loffhagen, D.; Matejčík, Š. Electron attachment to oxygen in nitrogen buffer gas at atmospheric pressure. The European Physical Journal D 2013, 67.

(30) Phelps, A. V. Laboratory studies of electron attachment and detachment processes of aeronomic interest. Canadian Journal of Chemistry 1969, 47, 1783-1793.

(31) Moruzzi, J. L.; Phelps, A. V. Survey of Negative-Ion-Molecule Reactions in O2, CO2, H2O, CO, and Mixtures of These Gases at High Pressures. The Journal of Chemical Physics 1966, 45, 4617-4627.

(32) Ponomarev, A. A.; Aleksandrov, N. L. Monte Carlo simulation of electron detachment properties for O2- ions in oxygen and oxygen:nitrogen mixtures. Plasma Sources Science and Technology 2015, 24, 35001.

(33) Aleksandrov, N. L.; Bychkov, V. L.; Grachev, L. P.; Esakov, I. I.; Lomteva, A. Y. The Effective Ionization of Air and Oxygen in a Near-Critical Electric Field at High Pressures. Russian Journal of Physical Chemistry B, Focus on Physics 2008, 2, 1-6.

(34) Burch, D. S.; Geballe, R. Clustering of Negative lons in Oxygen. Physical Review 1957, 106, 188190.

(35) Hösl, A.; Häfliger, P.; Franck, C. M. Measurement of ionization, attachment, detachment and charge transfer rate coefficients in dry air around the critical electric field. Journal of Physics $D$ : Applied Physics 2017, 50, 485207.

(36) Shahin, M. M. Nature of charge carriers in negative coronas. Applied optics 1969, 8 Suppl 1, 106110.

(37) Itikawa, Y.; Mason, N. Cross Sections for Electron Collisions with Water Molecules. Journal of Physical and Chemical Reference Data 2005, 34, 1-22.

(38) Atkins, P. W.; Paula, J. de; Keeler, J. Atkins' physical chemistry; Oxford University Press: Oxford, New York, 2018.

(39) Wannier, G. H. Motion of Gaseous lons in Strong Electric Fields. Bell System Technical Journal 1953, 32, 170-254.

(40) Fehsenfeld, F. C.; Ferguson, E. E. Laboratory studies of negative ion reactions with atmospheric trace constituents. The Journal of Chemical Physics 1974, 61, 3181-3193.

(41) Arshadi, M.; Kebarle, P. Hydration of $\mathrm{OH}$ - and O2- in the gas phase. Comparative solvation of $\mathrm{OH}$ by water and the hydrogen halides. Effects of acidity. The Journal of Physical Chemistry 1970, 74, 1483-1485.

(42) Payzant, J. D.; Kebarle, P. Kinetics of Reactions Leading to O2-(H2O)n in Moist Oxygen. The Journal of Chemical Physics 1972, 56, 3482-3487.

(43) Keesee, R. G.; Lee, N.; Castleman, A. W. Properties of clusters in the gas phase. 3. Hydration complexes of carbonate(1-) and bicarbonate(1-) ions. Journal of the American Chemical Society 1979, 101, 2599-2604.

(44) Fahey, D. W.; Böhringer, H.; Fehsenfeld, F. C.; Ferguson, E. E. Reaction rate constants for $\mathrm{O}-2(\mathrm{H} 2 \mathrm{O}) \mathrm{n}$ ions $\mathrm{n}=0$ to 4, with O3, NO, SO2, and CO2. The Journal of Chemical Physics 1982, 76, 1799-1805. 
(45) Dotan, I.; Davidson, J. A.; Streit, G. E.; Albritton, D. L.; Fehsenfeld, F. C. A study of the reaction O3- + $\mathrm{CO} 2-->\mathrm{CO} 3-+\mathrm{O} 2$ and its implication on the thermochemistry of $\mathrm{CO} 3$ and $\mathrm{O} 3$ and their negative ions. The Journal of Chemical Physics 1977, 67, 2874.

(46) Nagato, K.; Matsui, Y.; Miyata, T.; Yamauchi, T. An analysis of the evolution of negative ions produced by a corona ionizer in air. International Journal of Mass Spectrometry 2006, 248, 142-147. (47) Lifshitz, C.; Wu, R. L. C.; Tiernan, T. O.; Terwilliger, D. T. Negative ion-molecule reactions of ozone and their implications on the thermochemistry of O3-. The Journal of Chemical Physics 1978, $68,247$.

(48) Hierl, P. M.; Paulson, J. F. Translational energy dependence of cross sections for reactions of $\mathrm{OH}-(\mathrm{H} 2 \mathrm{O}) \mathrm{n}$ with $\mathrm{CO} 2$ and SO2. The Journal of Chemical Physics 1984, 80, 4890-4900.

(49) Hiraoka, K.; Yamabe, S. Formation of the chelate bonds in the cluster O2-(CO2)n,CO3-(CO2)n, and NO2-(CO2)n. The Journal of Chemical Physics 1992, 97, 643-650.

(50) Itikawa, Y. Cross Sections for Electron Collisions with Nitrogen Molecules. Journal of Physical and Chemical Reference Data 2006, 35, 31-53.

(51) Itikawa, Y. Cross Sections for Electron Collisions with Oxygen Molecules. Journal of Physical and Chemical Reference Data 2009, 38, 1-20.

(52) Yanallah, K.; Pontiga, F.; Fernández-Rueda, A.; Castellanos, A.; Belasri, A. Ozone generation by negative corona discharge: the effect of Joule heating. Journal of Physics D: Applied Physics 2008, 41, 195206.

(53) Yehia, A.; Mizuno, A. Expectation of ozone generation in alternating current corona discharges. Physics of Plasmas 2012, 19, 33513.

(54) Pignolet, P.; Hadj-Ziane, S.; Held, B.; Peyrous, R.; Benas, J. M.; Coste, C. Ozone generation by point to plane corona discharge. Journal of Physics D: Applied Physics 1990, 23, 1069-1072.

(55) Mason, N. J.; Skalny, J. D.; Hadj-Ziane, S. Experimental investigations and modelling studies of ozone producing corona discharges. Czechoslovak Journal of Physics 2002, 52, 85-94.

(56) Skalný, J. D.; Országh, J.; Matejčík, Š.; Mason, N. J. Ozone generation in positive and negative corona discharge fed by humid oxygen and carbon dioxide. Physica Scripta 2008, T131, 14012.

(57) Gravendeel, B. B. Negative corona discharges : a fundamental study; Technische Universiteit Eindhoven, 1987.

(58) Appelhans, A. D.; Dahl, D. A. SIMION ion optics simulations at atmospheric pressure. International Journal of Mass Spectrometry 2005, 244, 1-14.

(59) Bork, N.; Kurtén, T.; Enghoff, M. B.; Pedersen, J. O. P.; Mikkelsen, K. V.; Svensmark, H. Ab initio studies of $\mathrm{O} 2-(\mathrm{H} 2 \mathrm{O}) \mathrm{n}$ and $\mathrm{O} 3-(\mathrm{H} 2 \mathrm{O}) \mathrm{n}$ anionic molecular clusters, $\mathrm{n} \leq 12$. Atmospheric Chemistry and Physics 2011, 11, 7133-7142.

(60) Böhringer, H.; Fahey, D. W.; Lindinger, W.; Howorka, F.; Fehsenfeld, F. C.; Albritton, D. L. Mobilities of several mass-identified positive and negative ions in air. International Journal of Mass Spectrometry and lon Processes 1987, 81, 45-65.

(61) Viehland, L. A.; Mason, E. A. Transport Properties of Gaseous Ions over a Wide Energy Range, IV. Atomic Data and Nuclear Data Tables 1995, 60, 37-95.

(62) Ellis, H. W.; Pai, R. Y.; McDaniel, E. W.; Mason, E. A.; Viehland, L. A. Transport properties of gaseous ions over a wide energy range. Atomic Data and Nuclear Data Tables 1976, 17, 177-210.

(63) Cumeras, R.; Figueras, E.; Davis, C. E.; Baumbach, J. I.; Gràcia, I. Review on ion mobility spectrometry. Part 2: hyphenated methods and effects of experimental parameters. The Analyst 2015, 140, 1391-1410.

(64) Nazarov, E. G.; Coy, S. L.; Krylov, E. V.; Miller, R. A.; Eiceman, G. A. Pressure effects in differential mobility spectrometry. Analytical chemistry 2006, 78, 7697-7706.

(65) Viehland, L. A. Gaseous Ion Mobility, Diffusion, and Reaction; Springer International Publishing: Cham, 2018. 
(66) Kirk, A. T.; Kobelt, T.; Spehlbrink, H.; Zimmermann, S. A Simple Analytical Model for Predicting the Detectable Ion Current in Ion Mobility Spectrometry Using Corona Discharge Ionization Sources. Journal of the American Society for Mass Spectrometry 2018, 29, 1425-1430.

(67) Hayhurst, C. J.; Watts, P.; Wilders, A. Studies on gas-phase negative ion/molecule reactions of relevance to ion mobility spectrometry: mass analysis and ion identification of the negative reactant ion peak in "clean" air. International Journal of Mass Spectrometry and Ion Processes 1992, 121, 127139.

(68) Mohnen, V. A. Negative ions in air-like gas mixtures. Pure and Applied Geophysics 1972, 100, 123-132. 